\title{
A Computational Study of Ivermectin and Doxycycline Combination Drug Against SARS-CoV-2 Infection
}

Dr. Meenakshi Rana ( $\nabla$ mrana@uou.ac.in )

Uttarakhand Open University

Pooja Yadav

Jaypee Institute of Information Technology

Papia Chowdhury

Jaypee Institute of Information Technology

\section{Research Article}

Keywords: COVID-19, SARS-CoV-2, Ivermectin, Doxycycline, 3CLpro

Posted Date: August 5th, 2021

DOI: https://doi.org/10.21203/rs.3.rs-755838/v1

License: (c) (i) This work is licensed under a Creative Commons Attribution 4.0 International License.

Read Full License 


\title{
A Computational Study of Ivermectin and Doxycycline Combination Drug against SARS- CoV-2 Infection Meenakshi Rana ${ }^{1 *}$, Pooja Yadav², Papia Chowdhury² \\ ${ }^{1}$ Department of Physics, School of Sciences, Uttarakhand Open University, Haldwani, 263139, Uttarakhand, India \\ ${ }^{2}$ Department of Physics and Materials Science and Engineering, Jaypee Institute of Information Technology, Noida 201309, Uttar Pradesh, India. \\ *Corresponding author: mrana@uou.ac.in
}

\begin{abstract}
In the present study, we have described how by using molecular docking and molecular dynamics (MD) simulation studies the combination drug of ivermectin and doxycycline can be used as a potential inhibitor for Severe Acute Respiratory Syndrome Coronavirus (SARS-CoV) virus. In lieu of unavailability of specific cure of coronavirus disease of 2019 (COVID-19) till now various possibilities for individual and combination drugs have been explored by the medical practitioners/scientists for the remedial purpose of $\mathrm{CoV}-2$ infections. $3 \mathrm{C}$-like protease $\left(3 \mathrm{CL}^{\mathrm{pro}}\right)$ is the main protease of SARS-CoV-2 virus which plays an essential role in mediating viral replication in the human body. $3 \mathrm{CL}^{\text {pro }}$ protein can serve as an attractive drug target. In this work, we have studied drug: $3 \mathrm{CL}^{\text {pro }}$ interactions by in-silico molecular docking and MD simulation approaches. Common and easily available antiviral drugs ivermectin, doxycycline and their combination can regulate $3 \mathrm{CL}^{\mathrm{pro}}$ protein's function due to its easy inhibition.
\end{abstract}

Keywords: COVID-19; SARS-CoV-2; Ivermectin; Doxycycline; 3CL pro 


\section{Introduction:}

In the year 2020, the COVID-19 disease has spread globally and it has become an ongoing pandemic. Reported by the World Health Organization (WHO), due to this pandemic disease, more than 35,659,007 numbers of active patients with 1,044,269 people have already died till 10 October 2020 (https://covid19.who.int/). WHO declared the COVID-19 as a global health emergency. This disease is caused by a member of the coronavirus family [1]. Coronavirus was first found in 1930 in domestic poultry [2]. After that they were identified as causing several diseases in humans such as; respiratory illness, neurological, liver diseases, etc. [3]. Till now seven categories of this virus were identified. Among the seven categories of coronavirus, four causes only common cold with mild symptoms and in very rare cases pneumonia, respiratory infections in infants and older people [4]. The other three categories are Severe Acute Respiratory Syndrome Coronavirus (SARS-CoV) [5], Middle East Respiratory Syndrome Coronavirus (MERS-CoV) [6] and lastly the new one known as SARS-CoV-2 [7] identified in 2003, 2012 and 2019 respectively. The international committee on taxonomy of viruses declared this new novel coronavirus as SARS-CoV-2 [8]. The SARS-CoV-2 is a single-stranded RNA virus and belongs to the Coronaviridae family having genome sequences of $79.5 \%$ sequence matching $[9,10]$. This shows that bats may be the carrier of this virus. The uniqueness of this virus is the presence of spike glycoproteins on its surface which gives a crown-like appearance of the virus structure. The crown-like spike protein surface of this virus can be easily visible with the help of electron microscopes. These spike proteins are a very significant part of SARS-CoV-2 [11] virus as they can easily interact with the human proteins which coats the inside of the nose and the cells of lungs. The interaction of spike protein and human protein causes change in spike protein of CoV-2 shape and causes the human receptor cell to swallow up the virus. Through the receptor binding domain (RBD), glycoproteins of the viruses start binding and entering to the host cells. The key receptor for SARS-CoV-2 in humans is angiotensin converting enzyme 2 (ACE2) [12]. After entering the host cell, different human protease like airway trypsin-like protease (HAT), cathepsins and trans membrane protease serine 2 (TMPRSS2) divide the glycoproteins of the virus and so the conformational alteration of the virus structure occurs. From this phase the transformed virus replicates itself very fastly through some cyclic processes [12] and starts infecting the neighboring cells like lung, heart, brain cells and many others. From studies, scientists showed that the spike glycoproteins of coronavirus attach on the cell surface of the ACE2 receptor in the human body and allows the virus's genetic material to enter the human cell [13]. Virus's genetic material proceeds to hijack the metabolism of the cell and help the virus to divide. 
To overcome this disease the whole world is in a race to find vaccines/drugs to attack this virus. Through clinical trials around 200 drugs and vaccines (approved by Food and Drug Administration). Covaxin, INO-4800, mRNA-1273, NVX-CoV2373, BBV152 etc. are some candidate vaccines that are currently under trials for COVID-19 [14]. In the eleven months since the SARS-CoV-2 virus werediscovered, the scientific community has put forward an extraordinary effort that has resulted in the creation vaccines. Similarly examples of some FDA approved drugs for COVID-19 are atazanavir, remdesivir, ritonavir, lopinavir, chloroquine, hydroxychloroquine (HCQ), cyclosporin, favipiravir etc. [15 -19 ]. Screening of potential drug from different medicinal plants extracts for SARS-CoV-2 is also going on [20-22]. Now according to most common treatment protocols since there is no detected and approved drug for COVID-19, patients with severe COVID-19 symptoms are usually treated by different purposed antiviral drugs as trial basis. Most of the above-mentioned drugs are usually antiviral in nature and are used for various viral diseases like: HIV medication, influenza, MERS and SARS diseases or for enhancing the immune system of human life [23-26]. Nowadays to identify potential drugs for various diseases, the concept of drug repurposing is widely used. Drug repurposing is an approach to find out the new uses for already available drugs that are originally developed for specific diseases [27]. Drug repurposing process has already proved to be very effective since many drugs have multiple protein targets and genetic factors; molecular pathways which can be shared by diverse diseases. For many years repurposing of drugs have been used such as favipiravir drug used for influenza virus, sofosbuvir drug used for hepatitis $\mathrm{C}$ virus have a strong repurposing prospective against Zika and Ebola [28], drugs oseltamivir, lopinavir, nelfinavir, atazanavir and ritonavir have been used for the treatment SARS and MERS [29,30]. But these drugs have their own toxicity related issues. On the other hand, some immunomodulatory plasma-based therapies are in use. Some food nutrients, herbal medicines having antiviral and immunity building properties are considered as an alternative of COVID-19 therapies [31,32]. In the same way, a repurposing of combination drugs with ribavirin, lopinavir, and ritonavir have already been anticipated for the COVID-19 patients [40]. Lopinavir and ritonavir combination are already in use for HIV treatment. However, the efficacy of the vaccines are almost $70-80 \%$. So there is an urgent and strong requirement for a newly invented drug/repurposed drug/combination drug to fight the disease.

A combination drug includes two or more than two active ingredients mixed in a single dose form. For many years combination of drugs has been used for treating diseases such as 
aspirin/paracetamol/caffeine combination (Excedrin) is used for the treatment of headache and migraine [33], Carbidopa/levodopa/entacapone is used for the treatment of Parkinson's disease [34], and indacaterol/mometasone, used for the treatment of asthma [35]. Combination drug therapy is applied for many diseases such as: tuberculosis, leprosy, cancer, bacterial infections, malaria, and for many viral diseases like influenza, HIV/AIDS etc. [36]. Recently two combination drugs of Nitazoxanide/azithromycin [37] and another combination drug: lopinavir/oseltamivir/ritonavir are [38] being largely in use by medical practitioners to fight against SARS-CoV-2 infections. There are several advantages to the combination of drugs. They are increased action of drugs and efficiency, increase the efficiency of the therapeutic effect, reduced cost and side effects. However, combinations of drugs also include some disadvantages. Dose must be given in some fixed ratio otherwise mismatched pharmacokinetics may increase severe toxicity effects. Though several clinical trials are underway to identify drugs against SARS-CoV-2, but still currently there is availability of single approved drugs or vaccines. Urgent requirement of cure of current medical emergencies due to COVID-19 motivated us to investigate the possibility of inhibition of SARS-CoV-2 by using some repurposing of combination drugs: ivermectin and doxycycline.

In the present paper, we have described how the combination drug of ivermectin and doxycycline, can be used as a potential SARS-CoV-2 3CL pro inhibitor. 3CLpro is synonymous to another name which is Mpro (main protease). For several years ivermectin $\left(\mathrm{C}_{48} \mathrm{H}_{72} \mathrm{O}_{14}\right)$ is used to treat many infectious diseases in mammals [39].

Ivermectin is a antiparasitic agent and doxycycline is a broad-spectrum tetracycline antibiotic. Ivermectin have also antiviral activity against both RNA and DNA viruses [40]. Recently in April 2020, the in-vitro activity of Ivermectin against SARS-CoV-2 was reported [41]. Ivermectin's antiviral mechanism of action in COVID-19 may be block the activity of $\alpha / \beta 1$ receptors, which inhibiting viral protein transport in and out of the host nucleus[42]. Doxycycline was shown to have anti-SARS-CoV-2 activity in contaminated Vero E6 cells in vitro[43]. It's antiviral activity may be mediated by upregulation of the zinc finger antiviral protein, which binds to viral messenger RNAs and inhibits viral RNA translation[44]. Furthermore, doxycycline's anti-inflammatory effects were thought to add to its effectiveness in pulmonary inflammatory conditions such as asthma, cystic fibrosis, bronchiectasis, and lung damage. Both of these drugs are low cost and safe[45]. The aim of the present study that the combination of ivermectin and doxycycline can be proved to be effective against SARS-CoV-2 so that medical professionals may have alternative tool to treat patients. We have performed molecular docking 
and molecular dynamics (MD) simulations to understand the interaction mechanism of the proposed drugs for COVID-19. We hope that this work will provide other researchers with an important investigation way to identify new COVID-19 treatment.

\section{Materials and Methods:}

\subsection{Protein structure preparation}

Coronavirus possesses a number of polyproteins (structural and nonstructural). Among them $3 \mathrm{CL}^{\text {pro }}$ is a key $\mathrm{CoV}$ enzyme which plays an important role in mediating viral replication and transcription with the help of its glycoprotein. To rapidly discover the targeted drugs for clinical use, researchers focused on identifying drug leads that target $3 \mathrm{CL}^{\text {pro }}$ protein of SARS-CoV-2 as it plays an important role for viral replication and transcription. In the present work, we have used one of $3 \mathrm{CL}^{\mathrm{pro}}$ proteases of CoV-2 virus in a complex with an inhibitor N3 (PDBID: 6LU7) [46,47] as the target protein. 6LU7 has been shown to be a promising target for designing COVID-19 drugs. We have chosen 6LU7 for checking the inhibiting and binding properties of it with the ivermectin and doxycycline drugs. The structure of SARS-CoV-2 protease (PDB ID: 6LU7) was used as a receptor and retrieved from Protein Data Bank (http://www.rcsb.org/) [48,49] and are shown in Figure 1 (a). We have removed water and hydrogen from it. All the existing properties of the drugs are described in Table 1. For the preparation of protein, we have used Auto Dock and MG Tools of AutoDockVina software [50]. At first

existing lead components, water molecules and ions have been removed from it. Later the process of cleaning has been done. We have calculated the Gasteiger charges of protein structures and after that polar hydrogen have been introduced. Then the non-polar bonds were merged and rotatable bonds were defined. Finally, by using Discovery studio 2020 [51] the intrinsic ligands were detached from the protein molecules and the final protein molecule was saved in the PDB format (Figure 2 a). 


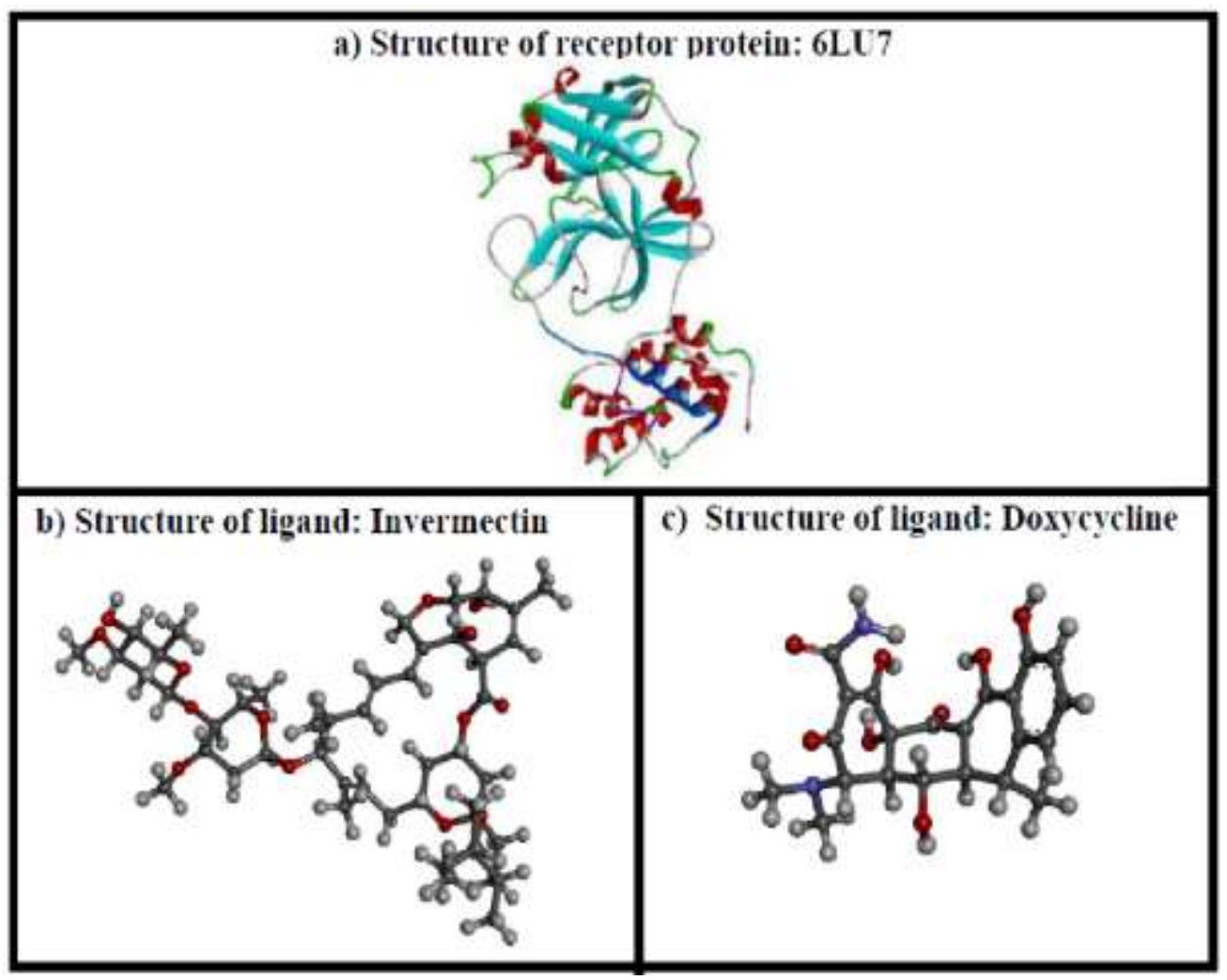

Figure 1. a) Structure of receptor (6LU7). b) Structure of ivermectin c) Structure of doxycycline (from Protein data bank and Gauss view). In the figure red color: oxygen atom, blue: nitrogen atom, gray color: carbon atom.

For target protein by visualizing the dihedral angles $\psi$ against $\varphi$ of amino acid residues, Ramachandran plots have been drawn (Figure 2b). It predicted permissible and disfavored values of $\psi$ and $\varphi$. Figure $2 b$ shows Ramachandran plots for 6LU7; the plot specifies localization on chain residues, which reflect the consistency of the protein structure, implying effective and accurate docking capacity. 
a) Target Protein (6LU7)

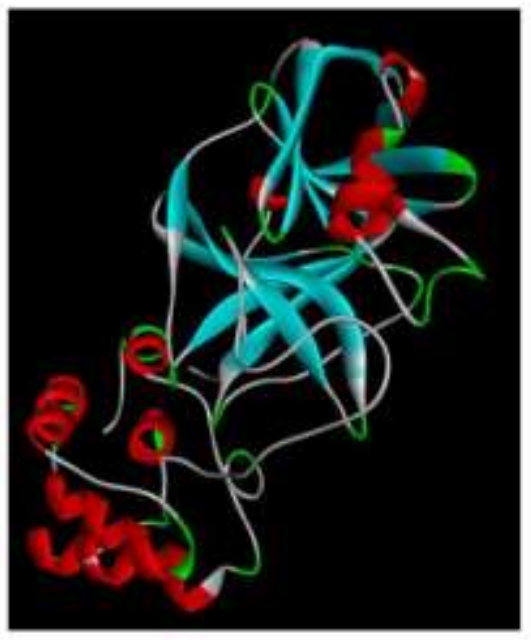

b) Ramachandran plot for protein (6LU7)

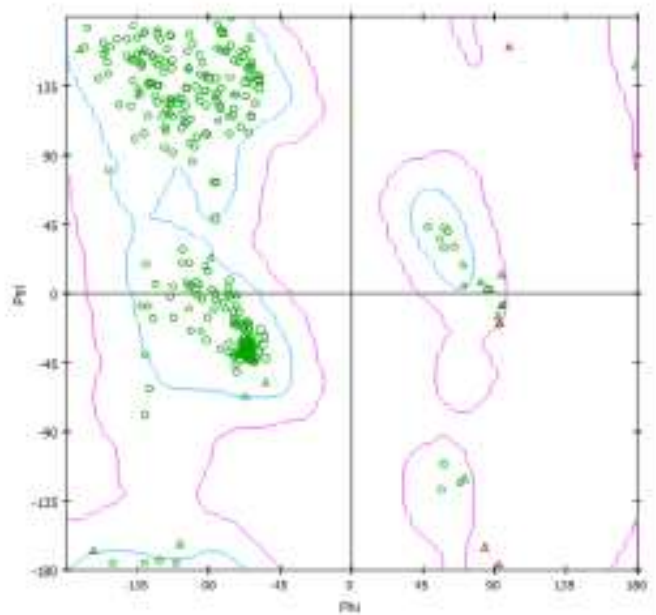

Figure 2. a) Target variable viral proteins (6LU7) SARS-CoV-2 protease enzyme as receptor and b) Ramachandran plot for the receptor protein.

\subsection{Ligand drug molecules preparations}

Structures of the drug molecules were downloaded from Drug Bank in pdb format. Then these structure were fully optimized by using the Gaussian 09 program [52]. We have used the optimized structure for docking analysis as they provide better results than unoptimized one. The geometric optimization of all drug compounds were carried out using HartreeFock (HF) and STO 3G basis set.Gauss View 5 molecular visualization program was used for visualizing the optimized structure [53]. ADME-T properties of molecules were identified using Organic chemistry portal (http://www.organicchemistry.org/prog), a web based application for predicting in-silicoADME-T property. Protein-ligand interactive visualization and analysis was carried out in AutoDock 4.2 software on Windows 7 (64-bit).

For the present work, we have selected two potential ligand drugs: ivermectin $\left(\mathrm{C}_{48} \mathrm{H}_{72} \mathrm{O}_{14}\right)$ and doxycycline $\left(\mathrm{C}_{22} \mathrm{H}_{24} \mathrm{~N}_{2} \mathrm{O}_{8}\right)$. Detail structures of these molecules were downloaded from Drug Bank in pdb format (Figure 1 and Table 1). Different chemical, physical, drug likeness and pharmacokinetics properties obtained from SWISS ADME are shown in Table 1. Both the proposed drug molecules have molecular weight less than $875 \mathrm{gm} / \mathrm{mol}$ and topological polar surface area (TPSA) values less than 180 A. 2 (Table 1). All drug molecules have H-bond donors $\geq 6, \mathrm{H}$-bond acceptor $\geq 14$ and have low synthetic accessibility count, this suggests that they can be synthesized easily. Though these drugs violate some 
drug likeness properties, still the availability of these drugs in the drug industry motivates us to consider these as potential inhibitors. The ligand file in pdbqt format is needed for molecular docking study with AutoDock Tools. AutoDock Tools 1.5.6 [54] have been used to save ligands in pdbqt format.

\subsection{Methods: Molecular docking and Molecular dynamics simulations}

To predict the target and drug interactions, molecular docking is commonly used in simulation. It minimizes the energy and calculates the binding energy of the interactions. In the molecular docking simulation, we normally make out the best pose of the ligand towards the receptor protein with the help of scoring functions [55]. Molecular docking can show the possibility of any biochemical reaction or whether a drug is docked with the receptor protein or not. The AutoDockvina with the best fitted parameters binding modes: 9, exhaustiveness: 8, applied maximum energy difference: $3 \mathrm{kcal} / \mathrm{mol}$ and Grid box center with $x, y$, and $z$ coordinate of residue position of the protein is used for docking purpose [50]. Grid box was formed with centers of $\mathrm{x}, \mathrm{y}, \mathrm{z}$ coordinate of residue position of the receptor protein respectively. The value of the centers of $\mathrm{x}, \mathrm{y}$ and $\mathrm{z}$ coordinates were considered as $-10.729204 \AA$, 12.417653 $\AA$ and $68.816122 \AA$ with their sizes as $30 \AA$ each in the grid box having a radius of the

sphere.as $13.709159 \AA$. The criteria for choosing the best position from the docked 9 modes is the maximum nonbonded interaction, higher binding affinity (kcal/mol), dipole moment (Debye), dreiding energy and inhibition constant. Best ligand: protein pose is identified by knowing the types (H-bonds, hydrophobic bonds) and number of bonding between them. The drug which makes the maximum number of bonds with the target protein mostly shows better complex formation. For analyzing and visualizing non-bonded hydrogen bonds for different output poses, Discovery Studio visualizer 2020 version 20.1.0.19295 [51] have been used. After the analysis of individual docking, sequential docking is performed. For sequential docking, the grid box coordinates were set to the particular binding region of each drug with default grid spacing. In the procedure of sequential docking, the first ligand is docked and the complex is saved out as a single file, where the first ligand is considered part of the receptor. Docking is then carried out on this complex with the second ligand. The structural dynamics of receptor and inhibitor interaction and thermodynamics stability of ligand: protein have been investigated with the help of Linux based platform "GROMACS 5.1 Package" [56], Different thermodynamic parameters like temperature $(T)$, density $(\mathrm{D})$, potential energy $\left(\mathrm{E}_{\mathrm{pot}}\right)$, root mean square deviation (RMSD) for backbone, root mean square fluctuation (RMSF) for protein $\mathrm{C}_{\alpha}$ Solvent accessible surface area (SASA), intermolecular hydrogen bonds, interaction energies $(\Delta G)$ of the protein and drug complex have been find out with 
GROMOS43A2 force fields[57]. For topology creation, we have used "PRODRG" server. PRODRG works with the concept of charge groups, which are defined as a group of bonded atoms with an integer charge. To assign atomic charges it recognizes the charge groups first. After topology creation of protein and ligand, according to the procedure followed for MD simulation, aqueous solution simulations have been performed using the water model: TIP3P. For solvation process protein in apo state, protein:ligand complexes were solvated in a cubic box, with a buffer distance of $10 \AA$ and volume as $893,000 \mathrm{~A}^{3}$. For electrically neutralizing the system four $\mathrm{Na}^{+}$ions have been added. Then we minimize the energy in the vacuum. For energy minimization 50000 iterations have been taken. To check the stability of the system, we have been performed MD simulation for the period of 0 ps to 100000 ps. Number of particles (N), volume (V), and temperature (T) were constant under the 1 atmosphere pressure and $298 \mathrm{~K}$ temperature. We have used Lennard-Jones and Coulomb short range interaction for the nonbonded interactions. All simulations were performed using a Berendsen thermostat and barostat [58] with the coupling time of $0.1 \mathrm{ps}$ and $0.5 \mathrm{ps}$, respectively. Non-bonded interactions (electrostatic and LJ interaction) were calculated using a triple range scheme within a shorter range cutoff of $0.8 \mathrm{~nm}$. Graphical tool Origin pro has been used to study the simulated results. "Molecular Mechanics Poisson-Boltzmann Surface Area" (MMPBSA) method [59] sourced from GROMACS and APBS packageshave been used for calculating the interaction free energies $\left(\Delta \mathrm{G}_{\mathrm{bind}}\right)$ of the protein: drug complex. To predict binding energy, snapshots at every 100 ps between 0 and 100000 ps were collected. $\Delta \mathrm{G}_{\text {bind }}$ calculation usually begins after the MD simulation of the complex using the single trajectory approach. $\Delta \mathrm{G}_{\text {bindin }}$ the aqueous solvent, for the bound protein: ligand complex can be given as: $\Delta G_{b i n d, a q u}=\Delta H-T \Delta S \approx \Delta E_{M M}+\Delta G_{b i n d, \text { solv }}-T \Delta S$

$$
\begin{gathered}
\Delta E_{M M}=\Delta E_{\text {covalent }}+\Delta E_{\text {electrostatic }}+\Delta E_{\text {Van der Waals }} \ldots \ldots(2) \\
\Delta E_{\text {covalent }}=\Delta E_{\text {bond }}+\Delta E_{\text {angle }}+\Delta E_{\text {torsion }} \ldots \ldots \ldots \ldots \ldots \ldots \text { (3) } \\
\Delta G_{\text {bind,solv }}=\Delta G_{\text {polar }}+\Delta G_{\text {nonpolar } \ldots \ldots \ldots \ldots \ldots \ldots \ldots \ldots \ldots(4)} \ldots \ldots \ldots \ldots \ldots \ldots \ldots
\end{gathered}
$$

Where, $\Delta E_{M M}$ is the molecular mechanical energy changes in gas phase and is the sum of covalent $\Delta E_{\text {covalent }}$, electrostatic $\left(\Delta E_{\text {electrostatic }}\right)$, and van der Waals energy $\left(\Delta E_{\text {vander waals }}\right)$ changes. Covalent energy is the combination of bond angle and torsion and $\Delta G_{b i n d, s o l v}$ is separated into its polar and nonpolar contributions. $\Delta G_{b i n d, s o l v}$ is solvation free energy change and -T $\Delta \mathrm{S}$ conformational energy change due to binding.For RMSD and RMSF multiple simulations were performed independently to validate the results obtained. MD simulation can simulate in ps/ns or further finer temporal stead- 
fastness [60]. The MD simulation force field plays an important role for estimating the forces within the molecule (intramolecular force) and between two molecules (intermolecular force). These intermolecular and intramolecular forces used to calculate the potential energy of the molecules. The total energy of the system is given as the sum of bonded and non-bonded energy and given as below:

$$
\begin{aligned}
& E_{\text {total }}=E_{\text {bonded }}+E_{\text {non bonded }} \ldots \ldots \ldots \ldots \ldots \ldots \ldots \ldots \ldots \ldots \text { (5) } \\
& E_{\text {bonded }}=E_{\text {bond }}+E_{\text {angle }}+E_{\text {dihedral }} \ldots \ldots \ldots \ldots \ldots \ldots \ldots \ldots \ldots \text { (6) } \\
& E_{\text {non bonded }}=E_{\text {hydrogen bond }}+E_{\text {electrostatic }}+E_{\text {Van der Waals }} \ldots \ldots \ldots(7) \\
& E_{\text {electrostatic }}=E_{\text {coulombic }}+E_{\text {Lennard Jones }} \ldots \ldots \ldots \ldots \ldots \ldots \ldots \ldots \text { (8) }
\end{aligned}
$$

These equations show that the bonded energy is the combination of bond, angle and dihedral energies while nonbonded energy is the combination of hydrogen bond, electrostatic and van der waals energies (eq. 6, 7).

\subsection{Computational facility}

MD simulations and corresponding energy calculations have been computed using HP Intel Core i5 1035G1 CPU and 8 GB of RAM with Intel UHD Graphics and a 512 GB SSD.

\section{Results and discussion}

\subsection{Individual docking of drugs against SARS-CoV-2 protease}

In the present work, ivermectin and doxycycline drugs were docked to SARS-CoV- 2 main protease $\left(3 \mathrm{CL}^{\mathrm{pro}}\right)$. Ivermectin and doxycycline drugs confirm the RO5, which means Lipinski's rule of fiveand other drug likeness rules etc. Hence, we have shown their strong application as potential drugs reaching the market (Table 1).

Table 1. Molecular configuration and drug likeness properties of proposed ligand drug molecules for COVID-19 by SWISS ADME data.

\begin{tabular}{|l|c|c|}
\hline Pub Chem CID & $\mathbf{6 3 2 1 4 2 4}$ & $\mathbf{5 4 6 7 1 2 0 3}$ \\
\hline Name of Ligand & Ivermectin & Doxycycline \\
\hline \multicolumn{2}{|c|}{ PhysicochemicalProperties } \\
\hline Molecular Formula & $\mathrm{C}_{48} \mathrm{H}_{74} \mathrm{O}_{14}$ & $\mathrm{C}_{22} \mathrm{H}_{24} \mathrm{~N}_{2} \mathrm{O}_{8}$ \\
\hline Molecular Weight $(\mathrm{g} / \mathrm{mol})$ & $875.09 \mathrm{~g} / \mathrm{mol}$ & $444.43 \mathrm{~g} / \mathrm{mol}$ \\
\hline Hydrogen Bond Donor & & 6 \\
\hline
\end{tabular}




\begin{tabular}{|c|c|c|}
\hline Count & & \\
\hline $\begin{array}{l}\text { Hydrogen Bond Acceptor } \\
\text { Count }\end{array}$ & 14 & 9 \\
\hline Rotatable Bond Count & 8 & 2 \\
\hline $\begin{array}{l}\text { Topological Polar Surface } \\
\text { Area }\end{array}$ & $170.06 \AA^{2}$ & $181.62 \AA^{2}$ \\
\hline Heavy Atom Count & 62 & 32 \\
\hline Formal Charge & 0 & 0 \\
\hline Molar Refractivity & 230.77 & 110.91 \\
\hline \multicolumn{3}{|c|}{ Lipophilicity } \\
\hline $\log P_{\mathrm{o} / \mathrm{w}}(\mathrm{iLOGP})$ & 5.86 & 1.93 \\
\hline $\log P_{\mathrm{o} / \mathrm{w}}(\mathrm{XLOGP} 3)$ & 6.34 & 0.54 \\
\hline $\log P_{\mathrm{o} / \mathrm{w}}($ WLOGP $)$ & 5.60 & -0.50 \\
\hline $\log P_{\mathrm{o} / \mathrm{w}}($ MLOGP $)$ & 1.25 & -2.08 \\
\hline $\log P_{\mathrm{o} / \mathrm{w}}($ SILICOS-IT) & 2.72 & -0.98 \\
\hline Consensus Log $P_{\mathrm{o} / \mathrm{w}}$ & 4.35 & -0.22 \\
\hline \multicolumn{3}{|c|}{ Water Solubility } \\
\hline $\log S$ (SILICOS-IT) & -8.73 & -2.94 \\
\hline class & Poorly soluble & Soluble \\
\hline Solubility & $1.62 \mathrm{e}-06 \mathrm{mg} / \mathrm{ml} ; 1.85 \mathrm{e}-09 \mathrm{~mol} / \mathrm{l}$ & $5.07 \mathrm{e}-01 \mathrm{mg} / \mathrm{ml} ; 1.14 \mathrm{e}-03 \mathrm{~mol} / \mathrm{l}$ \\
\hline \multicolumn{3}{|c|}{ Pharmacokinetics } \\
\hline $\begin{array}{l}\text { Gastrointestinal } \\
\text { absorption }\end{array}$ & Low & Low \\
\hline BBB permanent & No & No \\
\hline P-gp substrate & Yes & Yes \\
\hline CYP1A2 inhibitor & No & No \\
\hline CP2C19 inhibitor & No & No \\
\hline Log $K_{\mathrm{p}}$ (skin permeation) & $-7.14 \mathrm{~cm} / \mathrm{s}$ & $-8.63 \mathrm{~cm} / \mathrm{s}$ \\
\hline \multicolumn{3}{|c|}{ Drug Likeness } \\
\hline Lipinski Rule & No; 2 violations: $\mathrm{MW}>500, \mathrm{NorO}>10$ & Yes; 1 violation: $\mathrm{NHorOH}>5$ \\
\hline Ghose Filter & $\begin{array}{l}\text { No; } 4 \text { violations: } \mathrm{MW}>480, \text { WLOGP }>5.6 \text {, } \\
\text { MR>130, \#atoms }>70\end{array}$ & No; 1 violation: WLOGP $<-0.4$ \\
\hline Veber (GSK) Rule & No; 1 violation: TPSA $>140$ & No; 1 violation: TPSA>140 \\
\hline Egan (phatmacial) Filter & No; 1 violation: TPSA>131.6 & No; 1 violation: TPSA>131.6 \\
\hline Muegge (Bayer) Filter & $\begin{array}{c}\text { No; } 4 \text { violations: } \mathrm{MW}>600, \text { XLOGP3>5, } \\
\text { TPSA }>150, \mathrm{H}-\mathrm{acc}>10\end{array}$ & No; 2 violations: TPSA>150, $\mathrm{H}-\mathrm{don}>5$ \\
\hline $\begin{array}{l}\text { Bioavailability (Abbott) } \\
\text { Score }\end{array}$ & 0.17 & 0.11 \\
\hline \multicolumn{3}{|c|}{ Medicinal Chemistry } \\
\hline $\begin{array}{l}\text { PAINS (Pan Assey } \\
\text { Interference Structures) }\end{array}$ & 0 alert & 0 alert \\
\hline Brenk & 1 alert: isolated_alkene & 1 alert: michael_acceptor_4 \\
\hline
\end{tabular}




\begin{tabular}{|l|c|c|}
\hline Leadlikeness & $\begin{array}{c}\text { No; 3 violations: } \text { MW>350, Rotors }>7, \\
\text { XLOGP3>3.5 }\end{array}$ & No; 1 violation: MW>350 \\
\hline Synthetic accessibility & 10.00 & 5.25 \\
\hline
\end{tabular}

For the first experienced inhibitor ivermectin is docked with $3 \mathrm{CL}^{\text {pro }}$, 6LU7. Based on molecular docking ivermectin: protein complex revealed 9 different poses. For finding out the best pose for the ligand and receptor complex formation, molecular docking simulation follows certain rules. The pose with highest negative values of binding energy, a greater number of hydrogen bonds and lowest value of dreiding energy and dipole moment considered as the best one. For ivermectin: protein complex, we have observed pose 3 is the better interacted position for ligand: protein complex with the binding affinity of $-6.9 \mathrm{kcal} / \mathrm{mol}$. We have also computed the dreiding energy of different poses, in order to confirm the most excellent docked site. The dreiding energy $(6,298.99)$ becomes minimum for the best docked 3 pose (Table 2).

To confirm the better interaction between ivermectin and protein, we have calculated the inhibition constant $\left(\mathrm{k}_{\mathrm{i}}\right)$. It normally indicates how potent drugs inhibitors are towards protein. The inhibition constant can be calculated using the following equation:

$$
k_{i}=e^{\frac{\Delta G}{R T}}
$$

where $\mathrm{G}$ is binding affinity, $\mathrm{R}$ is universal constant and $\mathrm{T}$ is the room temperature $(298 \mathrm{~K})$.

For the best docked 3 pose of ivermectin: protein complex, the obtained value of ki as $8.7 \times 10^{-6} \mathrm{M}$ which proves the strong attraction of ivermectin towards protein (Table 2). The strong interaction for best docked pose (3) was further confirmed by the number of weak non-bonded hydrogen bonded interactions and hydrophobic interactions present between protein: ligand complex structure. "Hydrogen bonding and hydrophobic interactions" always stabilize the ligands at the target protein site [61]. We have observed the presence of intermolecular hydrogen bonds and hydrophobic interaction between protein and ligand. For best poses of ivermectin: protein complex, the donor-acceptor surface and different possible interactions in 3D and 2D view are shown in Figure 3 a.

Same molecular docking approach has been done for doxycycline ligand with $3 \mathrm{CL}^{\text {pro }}$. In terms of their different parameters (binding affinity value, dreiding energy, dipole moment, inhibition constants, number of hydrogen bonds, hydrophobic bonds etc.), we have identified the best possible ligand: protein 
docked pose position (Table 2). For doxycycline: protein complex, pose 7 is the better interacted position with the binding affinity of $-6.4 \mathrm{kcal} / \mathrm{mol}$, dreiding energy; 6,063.5, dipole moment; 6.104 Debye, inhibition constant; $2.0 \times 10^{-5} \mathrm{M}$ and 7 number of hydrogen bonds (Table 2). Best pose of the donor-acceptor surface with their possible hydrogen bonding and hydrophobic interactions 3D and 2D view are shown in Figure 3b. Our result shows that out of two possible ligand drug structures, ivermectin represents the best potentiality to inhibit with the SARS 3CL pro (6LU7) by its best docking affinity compared to the doxycycline. Good binding mode of interactions of ivermectin: protein complex also verified by its less binding energy, minimum inhibition constant value as compared to doxycycline. Both the drug molecules showed good stability as a complex with the targeted protein. These drug molecules also satisfy the required drug likeness properties according to Ro5, Veber etc. rules, polar surface areas and $\log \mathrm{P}$ values.

Table 2. Interaction factor for Ivermectin and Doxycycline with receptor (6LU7). Drug ivermectin represented as I, doxycycline represented as D and ivermectin + doxycycline represented as drug.

\begin{tabular}{|c|c|c|c|c|c|}
\hline Protein & $\begin{array}{c}\text { Binding } \\
\text { affinity } \\
\text { (kcal/mol) }\end{array}$ & $\begin{array}{l}\text { Hydrogen bonded interaction (donor: acceptor, distance in } \AA \text { ) } \\
\text { [Type of bond] }\end{array}$ & $\begin{array}{c}\text { Dipole } \\
\text { moment } \\
\text { (ligand) } \\
\text { Debye }\end{array}$ & $\begin{array}{c}\text { Dreiding } \\
\text { energy } \\
\text { (protein+lig } \\
\text { and) }\end{array}$ & $\begin{array}{c}\text { Inhibition } \\
\text { constant } \\
\text { (M) }\end{array}$ \\
\hline \multicolumn{6}{|c|}{ docking (Ivermectin) } \\
\hline 6LU7 & -6.9 & $\begin{array}{l}\text { (A:THR25:HG1-:I:O, 2.87667) [Conventional Hydrogen Bond] } \\
\text { (A:THR26:HN-: I:O, 2.03169) [Conventional Hydrogen Bond] } \\
\text { (A:ASN142:HD22-: I:O,2.79324)[Conventional Hydrogen Bond] } \\
\text { (:I:H-A:THR26:O, 2.45352) [Conventional Hydrogen Bond] } \\
\text { (:I:H-A:THR26:O, 2.13735) [Conventional Hydrogen Bond] } \\
\text { (A:THR25:CA- I:O, 3.40238) [Carbon atom Hydrogen Bond] } \\
\text { (A:PRO168:CA- I:O, 3.78628) [Carbon atom Hydrogen Bond] }\end{array}$ & 5.830 & $6,298.99$ & $8.7 \times 10^{-6}$ \\
\hline \multicolumn{6}{|c|}{ docking (Doxycycline) } \\
\hline 6LU7 & -6.4 & $\begin{array}{l}\text { (A:ASN142:HD22-:D:O, 3.03586)[Conventional Hydrogen Bond] } \\
\text { (:D:H-A:GLU166:O, 2.0088) [Conventional Hydrogen Bond] } \\
\text { (:D:H-A:GLN189:OE1, 2.12427) [Conventional Hydrogen Bond] } \\
\text { (:D:H-A:ASN142:OD1, 2.23539) [Conventional Hydrogen Bond] } \\
\text { (:D:C-A:HIS163:NE2, 3.59178) [Carbon atom Hydrogen Bond] }\end{array}$ & 6.104 & $6,063.5$ & $2.0 \times 10^{-5}$ \\
\hline \multicolumn{6}{|c|}{ Sequential docking (Ivermectin+Doxycycline) } \\
\hline 6LU7 & -7.4 & $\begin{array}{l}\text { (A:GLY143:HN-:drug:O, 2.122) [Conventional Hydrogen Bond] } \\
\text { (A:GLY143:HN-:drug:O, 2.86002) [Conventional Hydrogen Bond] } \\
\text { (A:SER144:HN-:drug:O2.32648) [Conventional Hydrogen Bond] } \\
\text { (A:SER144:HG-:drug:O2.1576) [Conventional Hydrogen Bond] } \\
\text { (A:CYS145:HN-:drug:O,2.57732) [Conventional Hydrogen Bond] } \\
\text { (A:GLU166:HN-:drug:O, 2.23187) [Conventional Hydrogen Bond] }\end{array}$ & 2.237 & $6,408.28$ & $3.7 \times 10^{-6}$ \\
\hline
\end{tabular}




\begin{tabular}{|l|l|l|l|l|}
\hline & $\begin{array}{l}\text { (drug:H- A:LEU141:O , 2.4969) [Conventional Hydrogen Bond] } \\
\text { (:drug:C-A:ASN142:OD1, 3.4013) [Conventional Hydrogen Bond] } \\
\text { (:drug:C-A:HIS41:NE2, 3.42481) [Conventional Hydrogen Bond] } \\
\text { (:drug:C-A:GLN189:OE1, 3.5951) [Carbon atom Hydrogen Bond] }\end{array}$ & & & \\
\hline
\end{tabular}

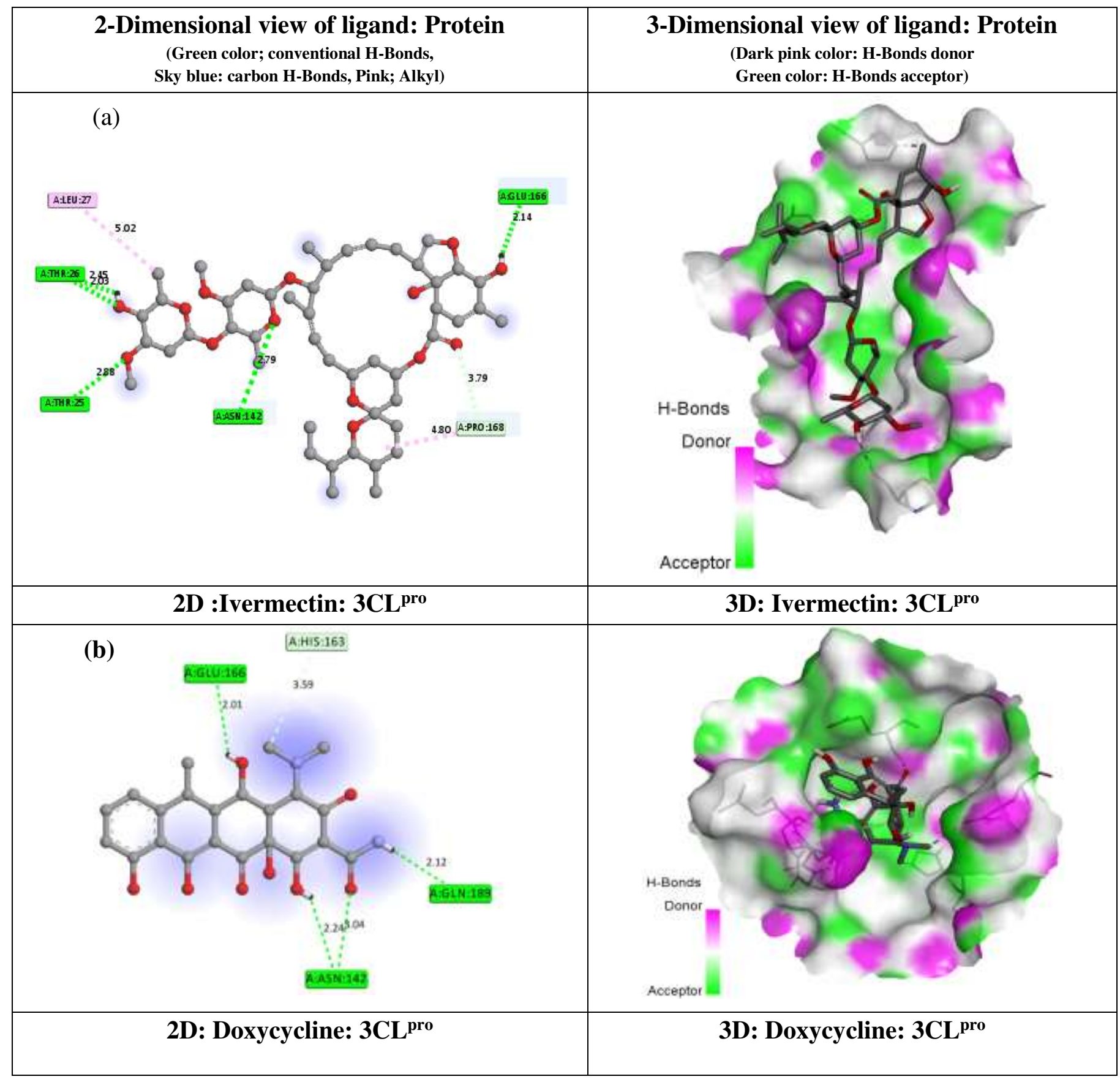

Figure 3. Donor: acceptor surface and possible types of interactions in best pose structures obtained from molecular docking for a) ivermectin: 6LU7 b) doxycycline: 6LU7 complex. 


\subsection{Sequential docking of two drugs against SARS-CoV-2 protease}

Individually, ivermectin and doxycycline drugs showed a good binding energy of $-6.9 \mathrm{kcal} / \mathrm{mol}$ and $-6.4 \mathrm{kcal} / \mathrm{mol}$, respectively. The docked ligand molecules with the protease $3 \mathrm{CL}^{\text {pro }}$ (6LU7) are shown in Figure 4a,b. The possible hydrophobic interactions and hydrogen bond between $3 \mathrm{CL}^{\text {pro }}$ of the two considered drugs obtained with individual docking are presented in Table 1 . We have performed sequential docking for checking the interaction of combinational drugs (two or more than two drugs mixed to form a single drug) and the target protein. This is helpful for detecting allosteric (place on protein where ligand that is not a substrate may bind) binding site. In the present work we have also checked the interaction of a combination of drugs (ivermectin+doxycycline) with the $3 \mathrm{CL}^{\mathrm{pro}}$. The combination drug binding energy was $-7.4 \mathrm{kcal} / \mathrm{mol}$ compared to the individual binding energies of -6.9 and $-6.4 \mathrm{kcal} / \mathrm{mol}$ for Ivermectin and Doxycycline respectively. While the binding energy difference between combination drug and individual drugs is definitely an improvement (Figure 4 c). In Figure 4, the red circle indicates the binding drug site with their binding energies respectively. The two most suitable nearest poses which validate the best pose 1 structure for ivermectin+doxycycline: 3CL ${ }^{\text {pro }}$ complex is shown in supporting document 1 (SD1). Since sequential docking of ivermectin and doxycycline drugs with $3 \mathrm{CL}^{\text {pro }}$ shows the better possibility of inhibition we have further studied the applicability of combination of these drugs as a potential drug by using MD simulation approach.

The stability of the particular complex is directly proportional to the number of nonbonded interactions. Larger the number of nonbonded interactions the more possibility of formation of complex structure (SD 2). Maximum number of conventional hydrogen bonds were observed for pose 1 of docked structure between ivermectin+doxycycline: $3 \mathrm{CL}^{\text {pro }}$ complex (Table 3 ). 

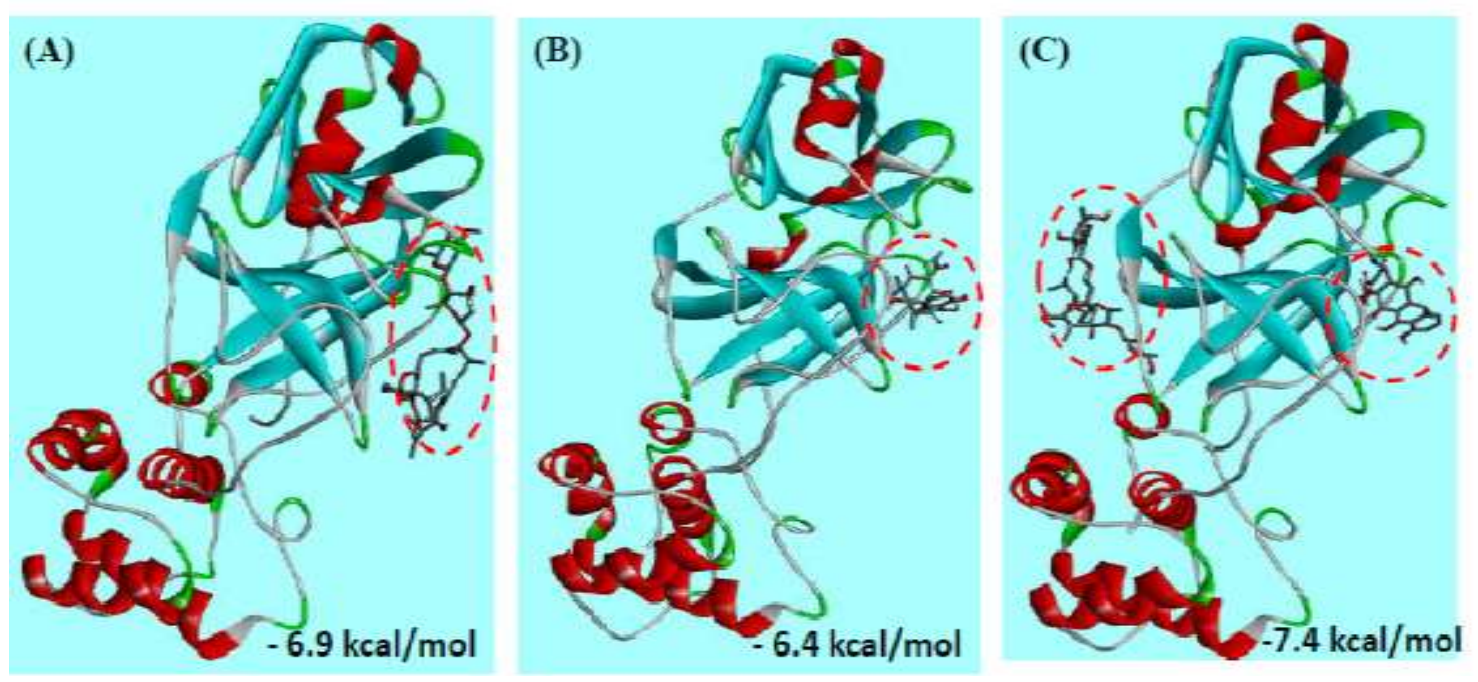

Figure 4. Binding energies of (A) ivermectin: $3 \mathrm{CL}^{\mathrm{pro}}(\mathbf{B})$ doxycycline: $3 \mathrm{CL}^{\text {pro }} \quad(\mathbf{C})$ ivermectin+doxycycline: $3 \mathrm{CL}^{\text {pro }}$ complex. The drug binding site is indicated by a red circle with their respective binding energies.

\subsection{MD simulation analysis}

To analyze the stability of the studied structure, MD simulation of the complexes (ivermectin: 3CL pro, doxycycline: $3 \mathrm{CL}^{\text {pro }}$, ivermectin+doxycycline: $3 \mathrm{CL}^{\text {pro }}$ ) have been studied for the period of $0 \mathrm{ps}$ to 100000 ps. For MD simulation, first we have to make all the structure energetically optimized (the potential energy should be minimum and negative with a maximum force value). Figure 5 represents energetically minimized protein and complex systems. We have obtained steady convergence of potential energy for all the cases. The comparison of the potential energy (Epot) of the stable structure of apo 6LU7 and in drugs: $3 \mathrm{CL}^{\text {pro }}$ complex has been done carefully. In the apo state $3 \mathrm{CL}^{\text {pro }}$ has Epot of $-1.27 \times 10^{6} \pm 56.7$ $\mathrm{kJ} / \mathrm{mol}$, while the complex ivermectin: $3 \mathrm{CL}^{\text {pro }}$, doxycycline: $3 \mathrm{CL}^{\text {pro }}$ and ivermectin+doxycycline: $3 \mathrm{CL}^{\text {pro }}$ has an average $E_{\text {pot }}$ of $-0.6110 \times 10^{5} \pm 2.62 \mathrm{Kcal} / \mathrm{mol},-0.60 \times 10^{5} \pm 3.34 \mathrm{Kcal} / \mathrm{mol},-0.594 \times 10^{5} \pm 12.66$ $\mathrm{Kcal} / \mathrm{mol}$ respectively (Table 3 ). Now all the structures having their lowest Epot values are ready for MD simulation. 


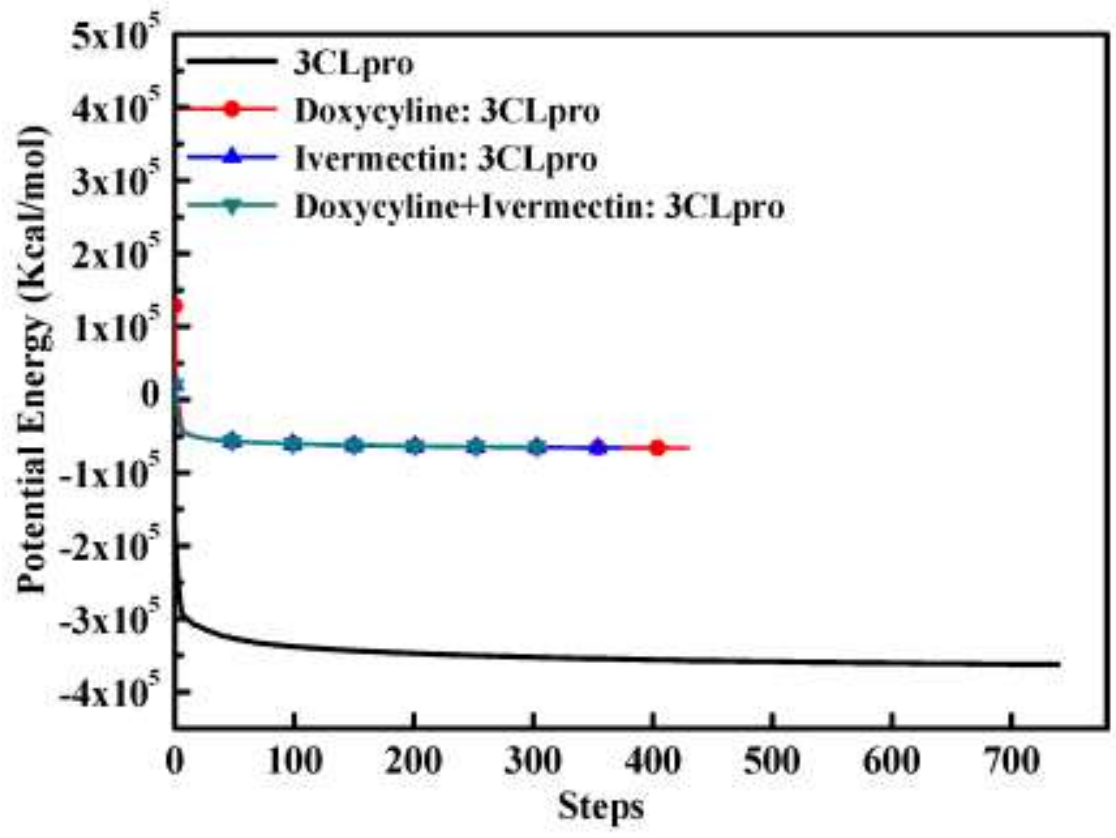

Figure 5: Potential energy surface for optimized geometry of apo protein, ivermectin: $3 \mathrm{CL}^{\text {pro }}$ complex, doxycycline: $3 \mathrm{CL}^{\text {pro }}$ complex and ivermectin+doxycycline: $3 \mathrm{CL}^{\text {pro }}$ complex.

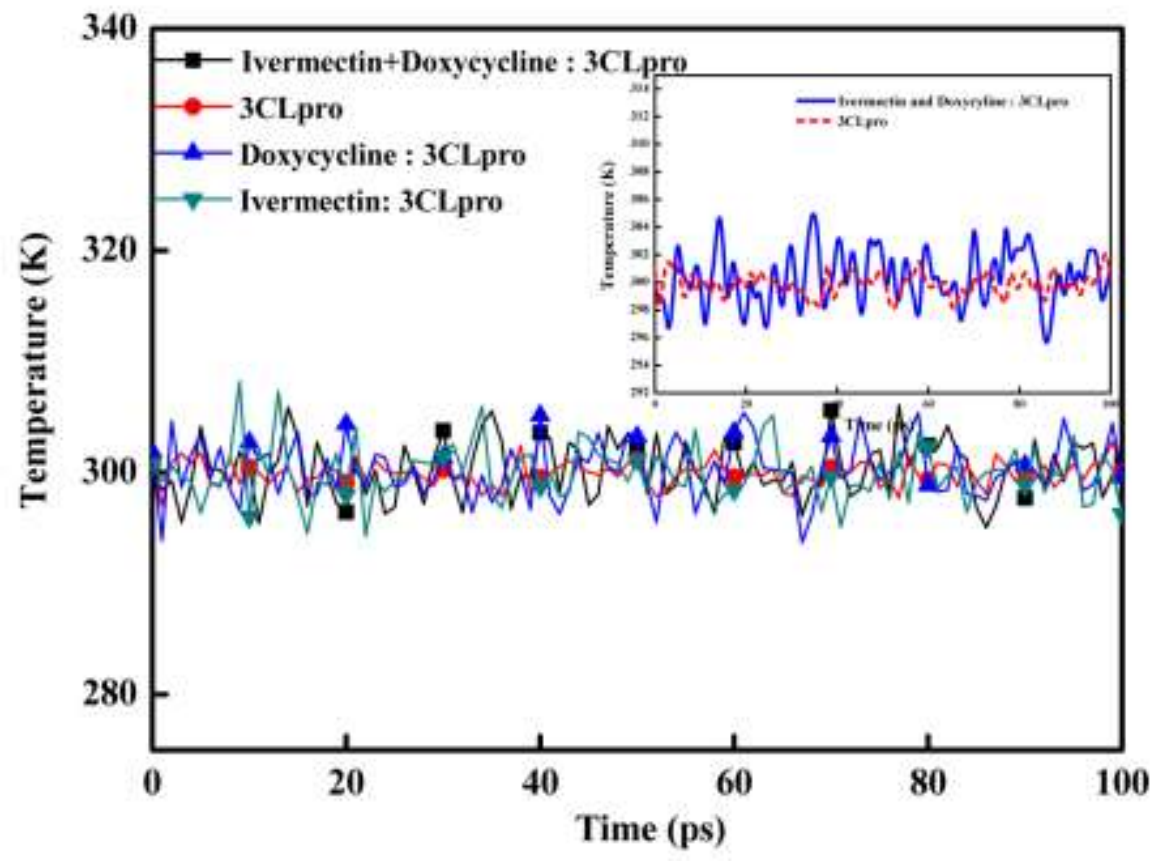

Figure 6: Temperature progression data for apo protein, ivermectin: $3 \mathrm{CL}^{\text {pro }}$, doxycycline: $3 \mathrm{CL}^{\text {pro }}$ and ivermectin+doxycycline: $3 \mathrm{CL}^{\mathrm{pro}}$ complex in water environment in GROMOS43A2 force fields.

To stabilized different parameters (temperature (T), pressure (P), density (D), volume (V) etc.) within a time scale of 100 ps to $10000 \mathrm{ps}$, we have further check the optimized drugs: 3CL pro structures 
equilibrated by NVT and NPT ensembles. It is observed that over the period of 100 ps time trajectory the temperature of the complex rapidly reached the stable at $300 \mathrm{~K}$ (room temperature) value (Figure 6). This temperature stability is maintained throughout the process. The temperature, pressure and density values of the system were also observed to be very stable over the period of time trajectory 100 ps (SD 3, SD 4). This concludes that the system is well equilibrated and prepared for MD simulation.

The compactness of the system with respect to time of apo protein and protein: ligand complex can be measured with the help of radius of gyration $\left(R_{g}\right)$ [62]. Normally for the stably folded protein structures the values of $R_{g}$ keeps a relatively steady for full time scale [63]. Whereas the $R_{g}$ values for the unfolded protein keeps changing for full time scale. Less compactness in the structures and high compactness with more stability exhibit a low and high $\mathrm{R}_{\mathrm{g}}$ value respectively. In the present paper we have observed the apo protein (3CL ${ }^{\text {pro }}$ ) has an average value of $R_{g}$ as $2.225 \mathrm{~nm}$ (SD 5, Table 3). Almost similar variation is observed with the proposed drugs: $3 \mathrm{CL}^{\text {pro }}$ complex (SD 5). This shows high compactness with more stability in the protein and drugs complexes (SD 5).

Further to validate the applicability of ivermectin, doxycycline and ivermectin+doxycycline ligands as proposed drug for COVID-19, we have simulated the SASA. SASA measures the area of exposure of the receptor to the solvents. The higher value of SASA indicates that the drug is more inserted into the water whereas, lower value represents that more drug is covered by the protein, which represents better complexation.In the present work, we have obtained the SASA mean value $22 \mathrm{~nm}^{2}$ for apo protein (SD 6, Table 3). Similarly, for all the proposed drug and $3 \mathrm{CL}^{\text {pro }}$ complex the mean value of SASA is $9 \mathrm{~nm}^{2}$. The low computed values of SASA observed for all drugs: protein complex shows that drug binding with the receptor protein increases the exposure of complexes to the protein (SD 6). Which validates the best complexation possibility. 

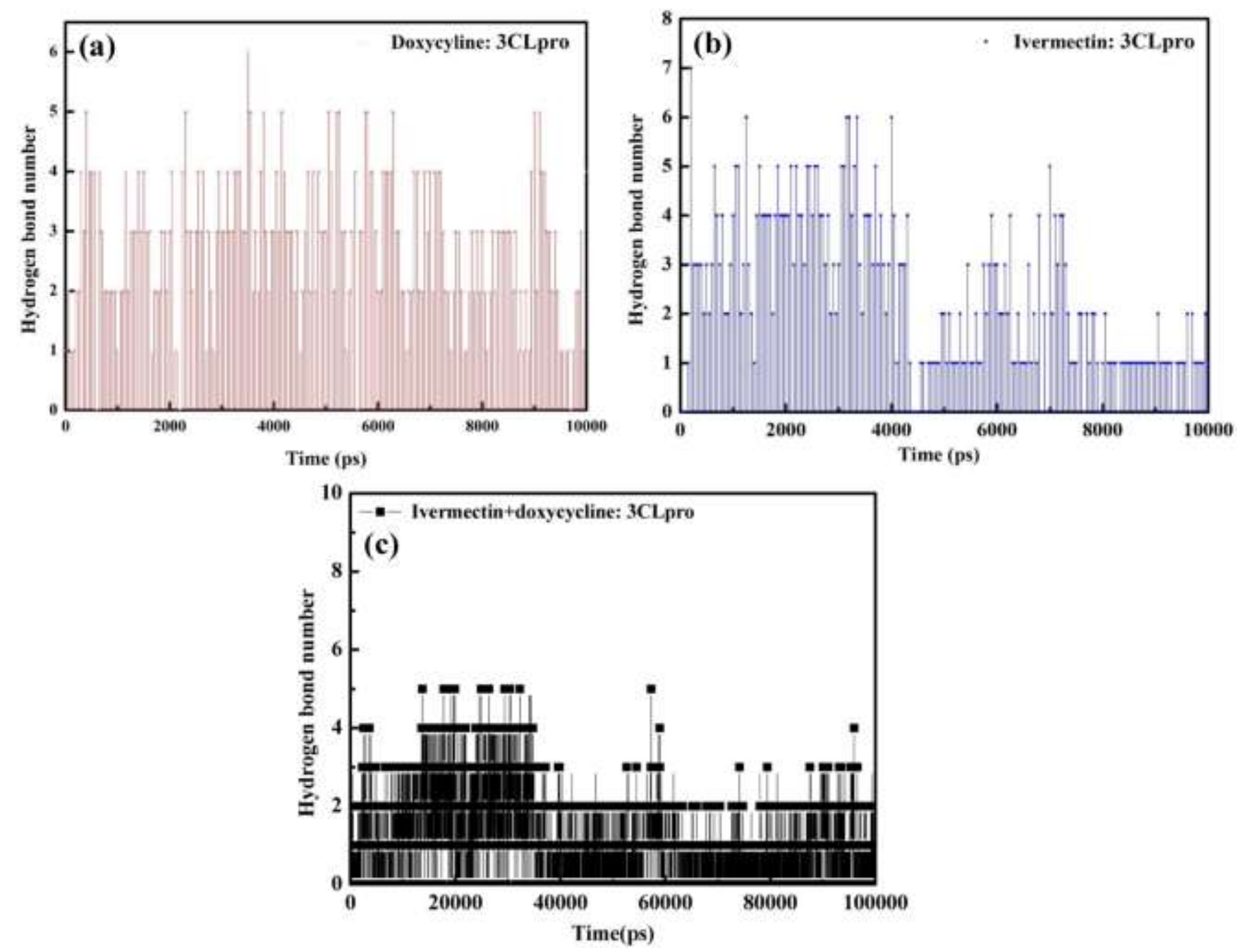

Figure 7: Hydrogen bond number for optimized geometry of a) ivermectin: 3CL ${ }^{\text {pro }}$ complex in time trajectory $0-10000 \mathrm{ps}$, b) doxycycline: 3CL pro complexin time trajectory 0-10000 ps, and c)ivermectin+doxycycline: $3 \mathrm{CL}^{\text {pro }}$ complex in time trajectory 0-100000 ps.

Intermolecular hydrogen bonding plays a significant role to get an idea about the binding strength between protein and drug. Ivermectin has a stable range of intermolecular hydrogen bonding with protein between 0 to 7 with an average value 3.5 in throughout the whole simulation process (Figure 7 , Table 3). Doxycycline has a range of intermolecular hydrogen bonding with protein between 0 to 6 in throughout the whole simulation process with an average value of 3 . However, the combination of both the drugs (ivermectin+doxycycline) has the highest stable range of intermolecular hydrogen bonding with protein between 0 to 12 with an average value 7 (Table 3). The intermolecular hydrogen bond number computed through MD simulation also perfectly matches with the docking results. This result 
clearly indicates that there is no conformational change around the probe drug systems in the binding site throughout the simulation process (Figure 7). The appearance of larger intermolecular hydrogen bonding in combination phase of ivermectin+doxycycline with the target $3 \mathrm{CL}^{\text {pro }}$ validates best binding phase compared to single phase binding with receptor protein.

We have used the Kolmogorov-Simornov method stepwise which allows us to make a determination as to whether a distribution matches the characteristics of a normal distribution. Beside $\mathrm{p}$ value, the method also show a test statistic (D), which provides a measurement of the divergence of given distribution from the normal distribution. For number of HBs the data shows the value of the K-S test statistic (D) is obtained as 0.14896 with $\mathrm{p}$ value $<0.0001$ with other parameters as: Mean: 1.86667, Median: 2, Standard Deviation: 1.400748, Skewness: 0.283449, Kurtosis: -0.686191 . For this case the p value appeared as less than 0.0001 which validate the significance of computed results.

RMSD 3D view

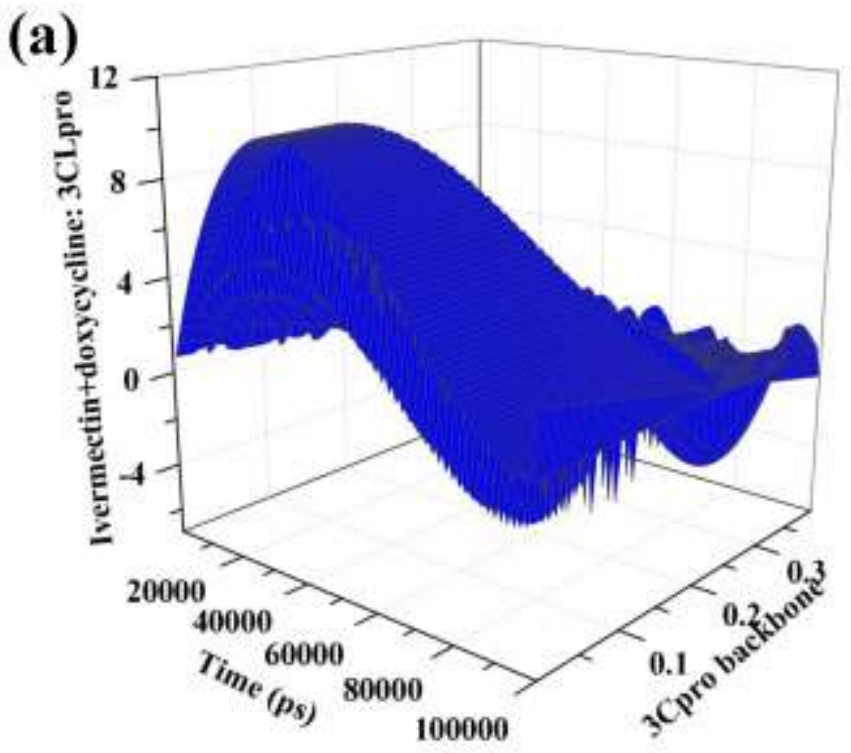

\section{RMSD 2D view}

(b)

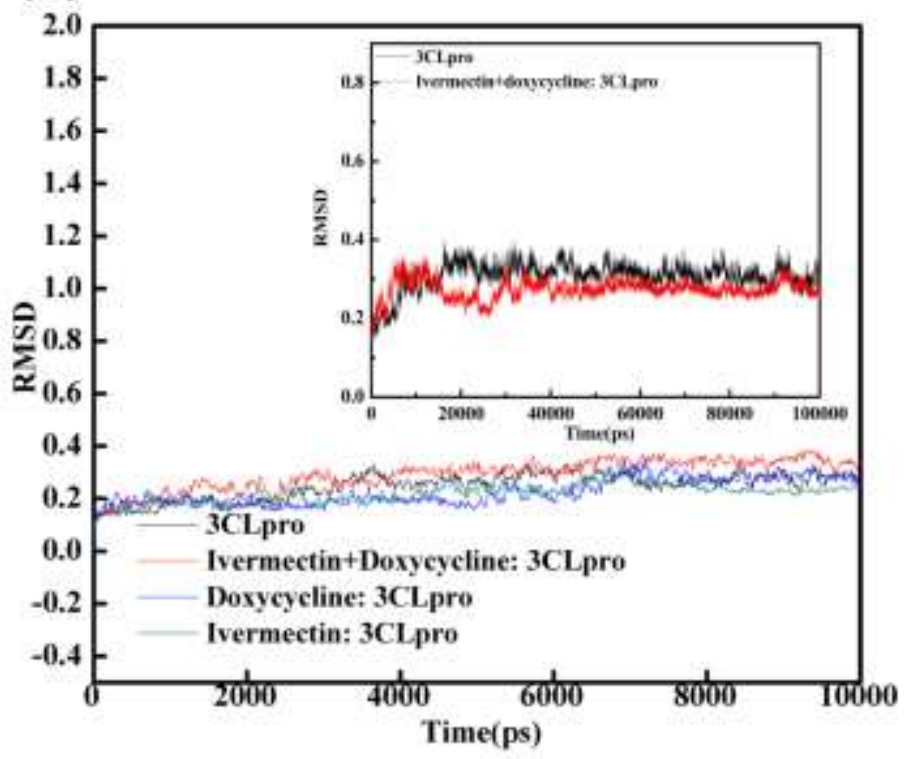

Figure 8. Root mean square deviation (RMSD) of receptor protein in its apo state, ivermectin: $3 \mathrm{CL}^{\text {pro }}$ complex, doxycycline: $3 \mathrm{CL}^{\text {pro }}$ and ivermectin+doxycycline: $3 \mathrm{CL}^{\text {pro }}$ complex a) $3 \mathrm{D}$ view in time trajectory 0-100000 ps and b) 2D view up to 10000 ps. Inset of 8b: 2D view of Root mean square deviation (RMSD) of receptor $3 \mathrm{CL}^{\text {pro }}$ in its apo state and ivermectin+doxycycline: 3CL ${ }^{\text {pro }}$ complex in time trajectory 0-100000 ps. 
RMSD corresponds to any change in the conformational stability of the protein: drug complex and in the protein dynamics. RMSD of the free protein and protein: ligand complex have been simulated to 100000 psby using MD simulations. RMSD and RMSF have been measured by using the GROMACS module at an interval of $1000 \mathrm{ps}$. RMSD variation of apo $3 \mathrm{CL}^{\text {pro }}$ lies in the range from 0.08 to $0.16 \AA$. Ivermectin: $3 C L^{\text {pro }}$, doxycycline: $3 C L^{\text {pro }}$, ivermectin+doxycycline: $3 \mathrm{CL}^{\text {pro }}$ complex, also ranges RMSD values from 0.08 to $0.16 \AA$ (Table 3 ). The RMSD value for complexes exactly matches with the apo protein. This provided a suitable basis for our study by the better stability with the probe drugs. Figure 8 represents the $2 \mathrm{D}$ and $3 \mathrm{D}$ view of RMSD values of $\mathrm{C} \alpha$ atoms of the apo protein and protein: ligand complex individually at various nanoseconds. The RMSD graph of all three ligands showed stability during the simulations (Figure 8). We have observed all the complexes are stable and no deviations of RMSD values were found throughout the simulations.

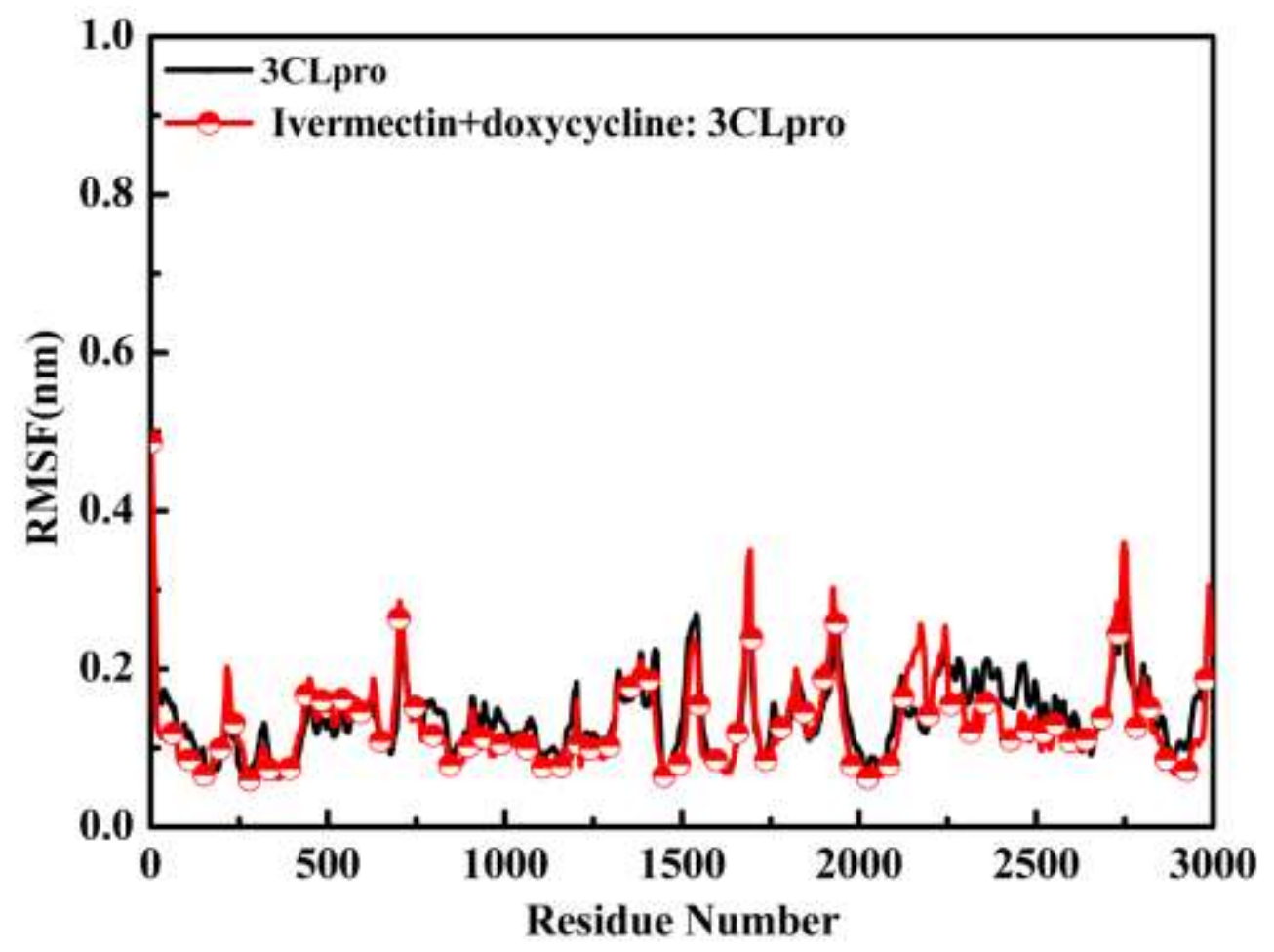

Figure 9. Graph of root mean square fluctuations (RMSF) of $3 \mathrm{CL}^{\text {pro }}$ in its apo state and in ivermectin+doxycycline: $3 \mathrm{CL}^{\text {pro }}$ complex.

For all amino acid residues with respect to $\mathrm{C} \alpha$ atom RMSF have been simulated. RMSF plot for $3 \mathrm{CL}^{\text {pro }}$ in its apo state and ivermectin+doxycycline: $3 \mathrm{CL}^{\text {pro }}$ complex have been shown in Figure 9, which depicts the fluctuations at the residue level. Residue fluctuation profile for both the cases shows a 
similar trend having an average RMSF value of $0.15 \AA$, which indicates that binding of both the drugs to the $3 \mathrm{CL}^{\text {pro }}$ had no key effect on the flexibility of the protein and was quite stable.

Table 3. MD simulation output parameters of 6LU7 in its apo state without any ligand and in the ivermectin+doxycycline: 6LU7 complex.

\begin{tabular}{|c|c|c|c|c|c|c|c|c|c|}
\hline \multirow[t]{2}{*}{$\begin{array}{l}\text { S. } \\
\text { No. }\end{array}$} & \multirow[t]{2}{*}{ Parameter } & \multicolumn{2}{|c|}{ apo Protein (3CLpro) } & \multicolumn{2}{|c|}{$\begin{array}{l}\text { Ivermectin: 3CLpro } \\
\text { complex }\end{array}$} & \multicolumn{2}{|c|}{$\begin{array}{l}\text { Doxycycline: } \\
\text { 3CLprocomplex }\end{array}$} & \multicolumn{2}{|c|}{$\begin{array}{l}\text { Ivermectin+Doxycycline: } \\
\text { 3CLpro complex }\end{array}$} \\
\hline & & Mean & Range & Mean & Range & Mean & Range & Mean & Range \\
\hline \multicolumn{10}{|c|}{ MD Simulation Result } \\
\hline 1. & $\begin{array}{l}\text { SR Coulombic Interaction } \\
\text { Energy (Kcal /mol) }\end{array}$ & NA & NA & $\begin{array}{l}-16.765 \\
\pm 3.34\end{array}$ & $\begin{array}{l}-32.50-- \\
5.01\end{array}$ & $\begin{array}{l}-21.411 \\
\pm 0.69\end{array}$ & $-17.68--25.33$ & $-20.29 \pm 3.10$ & $-21.51--9.56$ \\
\hline 2. & $\begin{array}{l}\text { SR Lennard-Jones } \\
\text { Interaction Energy (Kcal/ } \\
\text { mol) }\end{array}$ & NA & NA & $\begin{array}{l}-20.029 \\
\pm 4.06\end{array}$ & $\begin{array}{l}-32.265 \\
-11.71\end{array}$ & $\begin{array}{l}-22.919 \\
\pm 1.07\end{array}$ & $-20.79--27.00$ & $-29.920 \pm 0.74$ & $\begin{array}{l}-32.26-- \\
26.52\end{array}$ \\
\hline 3. & RMSD (nm) & 0.12 & $0.08-0.16$ & 0.12 & $\begin{array}{l}0.08- \\
0.16\end{array}$ & 0.12 & $0.08-0.16$ & 0.12 & $0.08-0.16$ \\
\hline 4. & Inter H-Bonds & NA & NA & 3.5 & $0-7$ & 3 & $0-6$ & 7 & $0-12$ \\
\hline 5. & Radius of gyration & $2.25 \pm 0.01$ & $2.25-2.26$ & 2.91 & $\begin{array}{l}2.91- \\
2.93\end{array}$ & 2.25 & $2.25-2.26$ & 2.91 & $2.91-2.93$ \\
\hline 6. & SASA $\left(\mathbf{n m}^{2}\right)$ & 22 & $19-26$ & 9 & $4-14$ & 9 & $4-14$ & 9 & $4-14$ \\
\hline \multicolumn{10}{|c|}{ MM/PBSA Results } \\
\hline 7. & $\begin{array}{l}\text { Potential Energy (Kcal } \\
\text { /mol) }\end{array}$ & $\begin{array}{l}-0.30 \times 10^{6} \\
\pm 13.55\end{array}$ & $\begin{array}{l}-1.74 \times 10^{5}- \\
-0.310 \times 10^{6}\end{array}$ & $\begin{array}{l}-0.6110 X \\
10^{5} \pm 2.62\end{array}$ & $\begin{array}{l}-1.26 \\
X 10^{4}-- \\
0.66 \\
X 10^{5}\end{array}$ & $\begin{array}{l}-0.60 X \\
10^{5} \pm 3.34\end{array}$ & $\begin{array}{l}-1.26 \times 10^{4}-- \\
0.66 \times 10^{5}\end{array}$ & $\begin{array}{l}-0.594 \times 10^{5} \\
\pm 12.66\end{array}$ & $\begin{array}{l}-1.26 \times 10^{4}- \\
0.66 \times 10^{5}\end{array}$ \\
\hline 8. & $\begin{array}{l}\text { Binding } \\
\operatorname{energy}(\Delta G)(\mathrm{Kcal} / \mathrm{mol})\end{array}$ & NA & NA & $\begin{array}{l}-2.085 \\
+/- \\
0.187\end{array}$ & NA & $\begin{array}{l}-1.590+/- \\
0.301\end{array}$ & NA & $\begin{array}{l}-2.544+/- \\
0.309\end{array}$ & NA \\
\hline 9. & $\begin{array}{l}\text { Van der Waal } \\
\operatorname{Energy}(\Delta \mathrm{Evdw})(\mathrm{Kcal} / \mathrm{mol})\end{array}$ & NA & NA & $\begin{array}{l}-0.016+/- \\
0.0007\end{array}$ & NA & $\begin{array}{l}-5.623 \\
+/- \\
0.375\end{array}$ & NA & $\begin{array}{l}-0.131 \quad+/- \\
0.060\end{array}$ & NA \\
\hline 10. & $\begin{array}{l}\text { Electrostatic } \\
\operatorname{Energy}(\Delta \text { Eelec })(\mathrm{Kcal} / \mathrm{mol})\end{array}$ & NA & NA & $\begin{array}{l}-0.0771 \\
+/- \\
0.005\end{array}$ & NA & $\begin{array}{l}-2.034 \\
+/- \\
0.149\end{array}$ & NA & $\begin{array}{ll}-0.114 \quad+/- \\
0.028\end{array}$ & NA \\
\hline 11. & $\begin{array}{l}\text { Polar Solvation Energy } \\
(\Delta \text { Epolar })(\text { Kcal } / \text { mol })\end{array}$ & NA & NA & $\begin{array}{l}-2.04+/- \\
0.196\end{array}$ & NA & $\begin{array}{l}6.628+/- \\
0.326\end{array}$ & $\mathrm{NA}$ & $\begin{array}{l}-2.325+/- \\
0.321\end{array}$ & NA \\
\hline 12. & $\begin{array}{l}\text { SASA Energy } \\
(\Delta \text { Eapolar })(\text { Kcal } / \mathrm{mol})\end{array}$ & NA & NA & $\begin{array}{l}0.04+/- \\
0.018\end{array}$ & NA & $\begin{array}{l}-0.582 \\
+/-0.042\end{array}$ & NA & $\begin{array}{l}0.038+/- \\
0.023\end{array}$ & NA \\
\hline
\end{tabular}

The short-range nonbonded interaction energy (Coulombic short range protein: ligand interaction energy terms and Lennard Jones short range protein: ligand interaction energy terms) quantify the strength of the interaction between probe drugs and protein. Addition of Coulombic interaction energy and Lennard Jones interaction energy provides the total interaction energy. Figure 10 a,b shows the contour map and 3D graph of obtained total interaction energy for the ivermectin+doxycycline: $3 \mathrm{CL}^{\text {pro }}$ complex. The 
average Coulombic interaction energy for ivermectin+doxycycline: 3CL pro complex comes out $20.29 \pm 3.10 \mathrm{Kcal} / \mathrm{mol}$ whereas the average Lennard-Jones interaction energy is $-29.920 \pm 0.74 \mathrm{Kcal} / \mathrm{mol}$ (Table 3). Table 3 represents all the Coulombic interaction energy and Lennard Jones interaction energy for individual drugs: protein complex and combination of drugs: protein complex. The comparison suggests that for all the complex formation, short-range Lennard-Jones has shown stronger effect on binding affinity than the short range coulombic interaction energy.
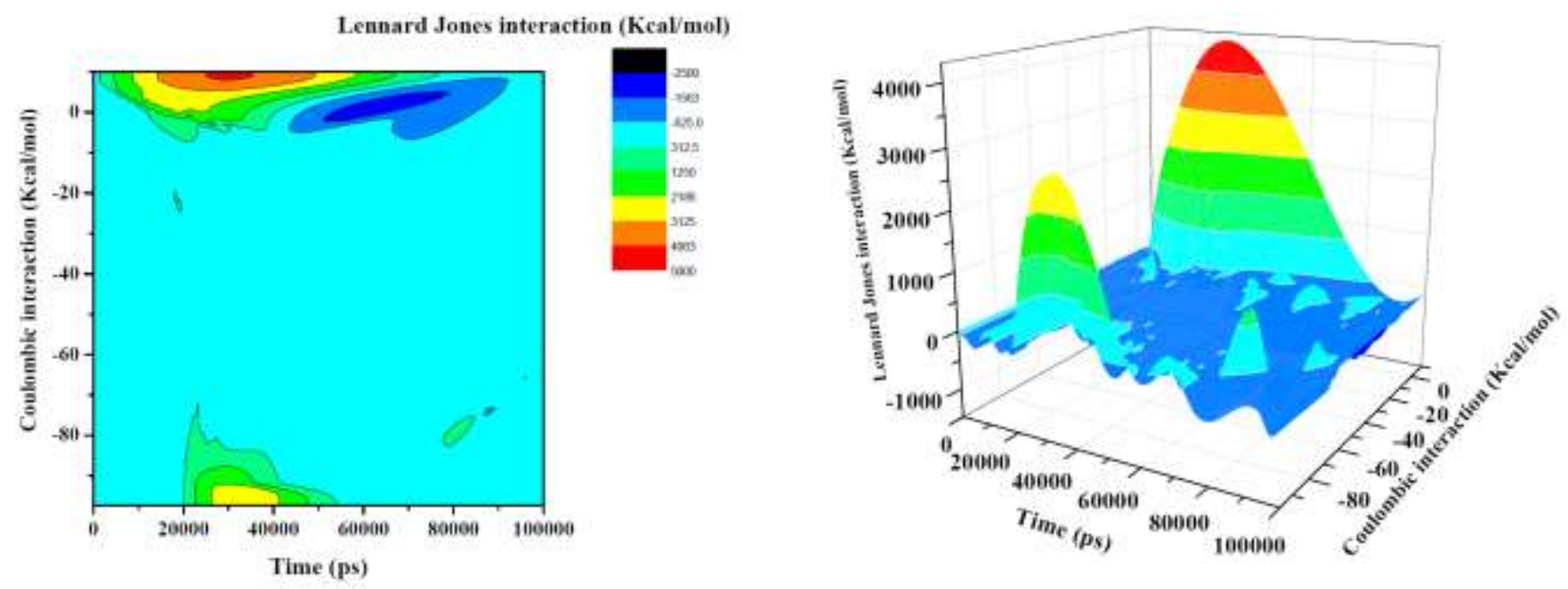

Figure 10: For ivermectin+doxycycline: 3CL pro complex a) contour plot of coulombic interaction energy and Lennard Jones interaction energy b) 3D representation of coulombic interaction energy and Lennard Jones interaction energy with respect to the time trajectory (0 to $100000 \mathrm{ps).}$

For the complex formation $\Delta \mathrm{G}$ indicates the non-bonded interaction energies which is the sum of comprehensive energies of individual components while the binding energy through molecular docking provides only binding energy of the complex formation. A variety of research works are currently underway to check the stability of various complex structures based on interaction energies using various quantum simulation techniques [64-66]. Figure 11 represents the $\Delta G$ values for ivermectin: $3 C L^{\text {pro }}$, doxycycline: $3 \mathrm{CL}^{\text {pro }}$ and ivermectin+doxycycline: $3 \mathrm{CL}^{\text {pro }}$ complex with respect to the time trajectory 0 ps to 10000 ps and inset of Figure 11 represents the $\Delta \mathrm{G}$ values for ivermectin+doxycycline: 6LU7 complex with respect to the time trajectory 0 ps to 100000 ps. The observed $\Delta G$ values for ivermectin+doxycycline: $3 \mathrm{CL}^{\text {pro }}$ complex is the lowest $(-2.544+/-0.309 \mathrm{Kcal} / \mathrm{mol})$ in comparison of other complexes $(\Delta \mathrm{G}$ for ivermectin $-2.085+/-0.187 \mathrm{Kcal} / \mathrm{mol}, \Delta \mathrm{G}$ for doxycycline $-1.590+/-0.301$ $\mathrm{Kcal} / \mathrm{mol}$ ) (Table 3, SD 7, SD 8, SD 9). The binding energy graph is going up (positive energy) for ivermectin+doxycycline: 3CL ${ }^{\text {pro }}$ complex after 8000 ps (Inset of Figure 11). However, it is going down 
(negative energy) for ivermectin+doxycycline: $3 \mathrm{CL}^{\text {pro }}$ complex after $10000 \mathrm{ps}$ (Inset of Figure 11). For $\Delta G_{\text {bind }}$ data the value of the K-S test statistic (D) is obtained as 0.50352 with p value $<0.00001$ with other paramaters as: Mean: -42.43665, Median: 0.327, Standard Deviation: 100.201162, Skewness: 1.924145, Kurtosis: 1.778898 . For $\Delta G_{\text {bind }}$ case the $\mathrm{p}$ value appeared as less than 0.0001 which validate the significance of computed results. This clearly indicates that ivermectin and doxycycline makes better complexation with the SARS-CoV-2 protein but the combination of these two drugs can make impressively best stable complex formation with receptor $3 \mathrm{CL}^{\text {pro }}$.

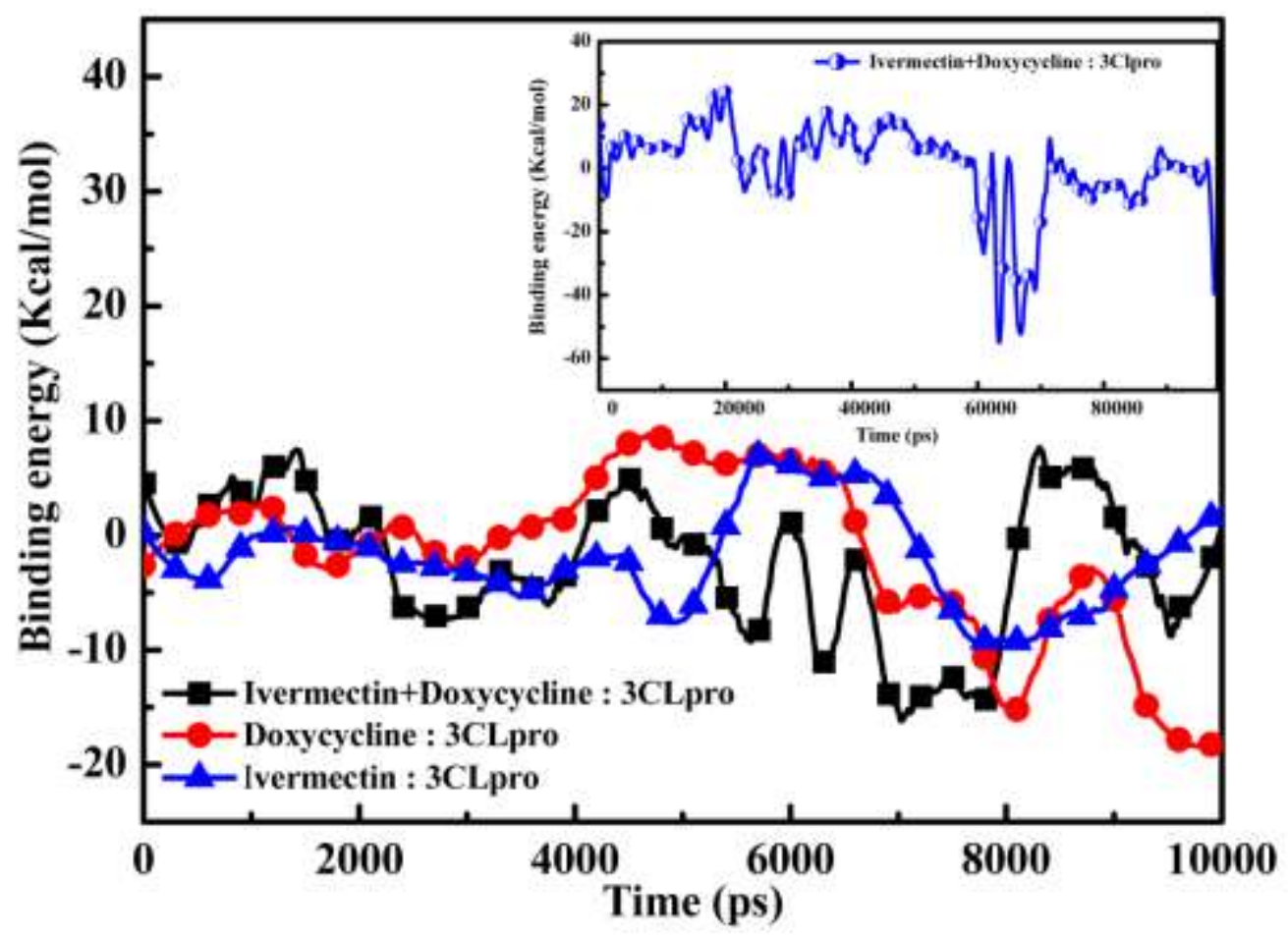

Figure 11: Total binding energy a) with respect to the time trajectory (0 to $10000 \mathrm{ps}$ ) for ivermectin: $3 \mathrm{CL}^{\text {pro }}$ complex, doxycycline: $3 \mathrm{CL}^{\text {pro }}$ complex and ivermectin+doxycycline: $3 \mathrm{CL}^{\text {pro }}$ complex. Inset of the graph shows the binding energy with respect to the time trajectory ( 0 to $100000 \mathrm{ps}$ ) for Ivermectin+doxycycline: $3 \mathrm{CL}^{\text {pro }}$ complex.

\section{Conclusions}

In conclusion, two drugs (ivermectin and doxycycline) were tested as potential inhibitors for COVID-19 main protease $3 \mathrm{CL}^{\text {pro }}$ via molecular docking. A strong inhibitory possibility of proposed drugs for SARS-CoV-2 protease $3 \mathrm{CL}^{\text {pro }}$ was verified by Gastrointestinal absorption, pharmacokinetics, drug likeness, and medicinal chemistry properties by using ADME analysis. From docked compounds, 
we have proposed that ivermectin and doxycycline demonstrated high binding affinity to the $3 \mathrm{CL}^{\text {pro }}$ and their combined docking increases the binding affinity on COVID-19 main protease. Strong binding affinity, lowest inhibition constant and existence of hydrogen bonded interaction established the better stability of ivermectin+doxycycline: $3 \mathrm{CL}^{\text {pro }}$ complex structure. Further studies also conducted on these compounds using MD simulations in order to get more reliable data. Many thermodynamic parameters ( $E_{\text {pot }}, T, V, D, R_{g}, S A S A$ energy) obtained by MD simulation also validated the complexation between ivermectin+doxycycline and $3 \mathrm{CL}^{\text {pro }}$. The backbone of the complex and free $3 \mathrm{CL}^{\text {pro }}$ illustrate similar RMSD and RMSF, which demonstrate the stability of the binding of drugs and protein. MD analyses have also confirmed the complexation between proposed drug and $3 \mathrm{CL}^{\text {pro }}$ by the lower values of binding energy. All simulated results establish that combination of drugs is a stronger candidate as a potential inhibitor for SARS-CoV-2 than considering each drug separately. Our present in-silico study would provide a new approach to the researchers working in the field of new drug finding against SARS-CoV2. However, a proper in-vivo and in-vitro rigorous research works are to be performed for the validation of our simulation work so that our recommended combination drug may be considered as a promising candidate for the drug design against COVID-19.

\section{Declarations}

Funding: Not applicable

Conflicts of interest/Competing interests: The authors declare that they have no known competing financial interests or personal relationships that could have appeared to influence the work reported in this paper.

Availability of data and material: Not applicable

Code availability: Not applicable

\section{Authors' contributions:}

Meenakshi Rana: Writing- Original draft preparation, Visualization, Investigation, Writing- Reviewing and Editing

Pooja: Data curation, Visualization, Investigation, Software, Validation

Papia Chowdhury: Conceptualization, Software, Methodology, Supervision 
References

1. Guo YR, Cao QD, Hong ZS, Tan YY, Chen SD, Jin HJ, Tan KS, Wang DY, Yan Y, The origin, transmission and clinical therapies on coronavirus disease 2019 (COVID-19) outbreak-an update on the status. Military Medical Research, 2020; 7:1-10.

2. Estola T, Coronaviruses, a new group of animal RNA viruses. Avian Dis. 1970; 14:330-336.

3. Liu HL, Lin JC, Ho Y, Chen CW, Homology models of main proteinase from coronavirus. Chem. Phys. Lett. 2005; 401:24-29.

4. McIntosh K, Chao RK, Krause HE, Wasil R, Mocega HE, Mufson MA. Coronavirus infection in acute lower respiratory tract disease of infants. Journal of Infectious Diseases. 1974;130:502-7.

5. Rota PA, Oberste MS, Monroe SS, Nix WA, Campagnoli R, Icenogle JP, Penaranda S, Bankamp B, Maher K, Chen MH, Tong S. Characterization of a novel coronavirus associated with severe acute respiratory syndrome. science. 2003;300(5624):1394-9.

6. Su S, Wong G, Shi W, Liu J, Lai AC, Zhou J, Liu W, Bi Y, Gao GF. Epidemiology, genetic recombination, and pathogenesis of coronaviruses. Trends in microbiology. 2016;24(6):490-502.

7. Huang C, Wang Y, Li X, Ren L, Zhao J, Hu Y, Zhang L, Fan G, Xu J, Gu X, Cheng Z. Clinical features of patients infected with 2019 novel coronavirus in Wuhan, China. The lancet. 2020;395(10223):497-506.

8. Gorbalenya AE, Baker SC, Baric R, Groot RJ, Drosten C, Gulyaeva AA, Haagmans BL, Lauber C, Leontovich AM, Neuman BW, Penzar D. Severe acute respiratory syndrome-related coronavirus: The species and its viruses-a statement of the Coronavirus Study Group.

9. Graham RL, Donaldson EF, Baric RS. A decade after SARS: strategies for controlling emerging coronaviruses. Nature Reviews Microbiology. 2013;11(12):836-48.

10. Van Der Hoek L, Pyrc K, Jebbink MF, Vermeulen-Oost W, Berkhout RJ, Wolthers KC, Wertheim-van Dillen PM, Kaandorp J, Spaargaren J, Berkhout B. Identification of a new human coronavirus. Nature medicine. 2004;10(4):368-73.

11. Hendaus MA, Jomha FA. Covid-19 induced superimposed bacterial infection. Journal of Biomolecular Structure and Dynamics. 2020: 1-7. https://doi.org/10.1080/07391102.2020.1772110.

12. Anand K, Ziebuhr J, Wadhwani P, Mesters JR, Hilgenfeld R. Coronavirus main proteinase $\left(3 C L^{p r o}\right)$ structure: basis for design of anti-SARS drugs. Science. 2003;300(5626):1763-7.

13. Belouzard S, Millet JK, Licitra BN, Whittaker GR. Mechanisms of coronavirus cell entry mediated by the viral spike protein. Viruses. 2012;4(6):1011-33.

14. https://www.who.int/emergencies/diseases/novel-coronavirus-2019/covid-19-vaccines

15. Drożdżal S, Rosik J, Lechowicz K, Machaj F, Kotfis K, Ghavami S, Łos MJ. FDA approved drugs with pharmacotherapeutic potential for SARS-CoV-2 (COVID-19) therapy. Drug resistance updates. 2020:100719.

16. Hendaus MA, Jomha FA. Covid-19 induced superimposed bacterial infection. Journal of Biomolecular Structure and Dynamics. 2020:1-0. 
17. Wang B, Guo H, Ling L, Ji J, Niu J, Gu Y. The chronic adverse effect of chloroquine on kidney in rats through an autophagy dependent and independent pathways. Nephron. 2020;144(1):53-64.

18. Zhang R, Mylonakis E. In inpatients with COVID-19, none of remdesivir, hydroxychloroquine, lopinavir, or interferon $\beta$-1a differed from standard care for in-hospital mortality. Annals of internal medicine. 2021; 174(2):JC17.

19. Baildya N, Ghosh NN, Chattopadhyay, AP. Inhibitory capacity of Chloroquine against SARSCOV-2 by effective binding with Angiotensin converting enzyme-2 receptor: An insight from molecular docking and MD-simulation studies. Journal of Molecular Structure. 2021;1230:129891.

20. Jairajpuri, DS, Hussain A, Nasreen K, Mohammad T, Anjum F, Rehman MT, Hassan MI, Identification of natural compounds as potent inhibitors of SARS-CoV-2 main protease using combined docking and molecular dynamics simulations. Saudi Journal of Biological Sciences. 2021; 28(4):2423-2431.

21. Baildya N, Khan AA, Ghosh NN, Dutta T, Chattopadhyay AP, Screening of potential drug from Azadirachta Indica (Neem) extracts for SARS-CoV-2: An insight from molecular docking and MDsimulation studies. Journal of molecular structure. 2021;1227:129390.

22. Verma AK, Kumar V, Singh S, Goswami BC, Camps I, Sekar A, Yoon S, Lee KW, Repurposing potential of Ayurvedic medicinal plants derived active principles against SARS-CoV-2 associated target proteins revealed by molecular docking, molecular dynamics and MM-PBSA studies. Biomedicine \& Pharmacotherapy. 2021;137;111356.

23. Dyall J, Gross R, Kindrachuk J, Johnson RF, Olinger GG, Hensley LE, Frieman MB, Jahrling PB. Middle East respiratory syndrome and severe acute respiratory syndrome: current therapeutic options and potential targets for novel therapies. Drugs. 2017;77(18):1935-66.

24. Cardoso WB, Mendanha SA. Molecular dynamics simulation of docking structures of SARSCoV-2 main protease and HIV protease inhibitors. Journal of molecular structure. 2021;1225:129143.

25. Leong HN, Ang B, Earnest A, Teoh C, Xu W, Leo YS. Investigational use of ribavirin in the treatment of severe acute respiratory syndrome, Singapore, 2003. Tropical Medicine \& International Health. 2004;9(8):923-7.

26. Leong HN, Chan KP, Khan AS, Oon L, Se-Thoe SY, Bai XL, Yeo D, Leo YS, Ang B, Ksiazek TG, Ling AE. Virus-specific RNA and antibody from convalescent-phase SARS patients discharged from hospital. Emerging infectious diseases. 2004;10(10): 1745.

27. Xue H, Li J, Xie H, Wang Y. Review of drug repositioning approaches and resources. International journal of biological sciences. 2018;14(10):1232.

28. Mercorelli B, Palù G, Loregian A. Drug repurposing for viral infectious diseases: how far are we?. Trends in microbiology. 2018;26(10):865-76. 
29. Dobson J, Whitley RJ, Pocock S, Monto AS. Oseltamivir treatment for influenza in adults: a meta-analysis of randomised controlled trials. The Lancet. 2015;385(9979):1729-37.

30. Lv L, Ren YL, Chen JC, Wu Q, Chen GQ. Application of CRISPRi for prokaryotic metabolic engineering involving multiple genes, a case study: controllable P (3HB-co-4HB) biosynthesis. Metabolic engineering. 2015;29:160-8.

31. Panyod S, Ho CT, Sheen LY. Dietary therapy and herbal medicine for COVID-19 prevention: A review and perspective. Journal of Traditional and Complementary Medicine. 2020; 10;420-427.

32. Chowdhury P. In silico investigation of phytoconstituents from Indian medicinal herb 'Tinosporacordifolia (giloy)'against SARS-CoV-2 (COVID-19) by molecular dynamics approach. Journal of Biomolecular Structure and Dynamics. 2020:1-8.

33. Hung IF, Lung KC, Tso EY, Liu R, Chung TW, Chu MY, Ng YY, Lo J, Chan J, Tam AR, Shum HP. Triple combination of interferon beta-1b, lopinavir-ritonavir, and ribavirin in the treatment of patients admitted to hospital with COVID-19: an open-label, randomised, phase 2 trial. The Lancet. 2020;395(10238):1695-704.

34. Yiğit A, Yardım Y, Çelebi M, Levent A, Şentürk Z. Graphene/Nafion composite film modified glassy carbon electrode for simultaneous determination of paracetamol, aspirin and caffeine in pharmaceutical formulations. Talanta. 2016;158:21-9.

35. Poulopoulos M, Waters C. Carbidopa/levodopa/entacapone: the evidence for its place in the treatment of Parkinson's disease. Core evidence. 2010;5:1.

36. Beeh KM, Kirsten AM, Tanase AM, Richard A, Cao W, Hederer B, Beier J, Kornmann O, van Zyl-Smit RN. Indacaterol acetate/mometasonefuroate provides sustained improvements in lung function compared with salmeterolxinafoate/fluticasone propionate in patients with moderate-tovery-severe COPD: results from a Phase II randomized, double-blind 12-week study. International Journal of Chronic Obstructive Pulmonary Disease. 2018;13:3923.

37. Whittaker E, López-Varela E, Broderick C, Seddon JA. Examining the complex relationship between tuberculosis and other infectious diseases in children: a review. Frontiers in pediatrics. 2019;7:233.

38. Kelleni MT. Nitazoxanide/azithromycin combination for COVID-19: A suggested new protocol for early management. Pharmacological research. 2020;157:104874.

39. Muralidharan N, Sakthivel R, Velmurugan D, Gromiha MM. Computational studies of drug repurposing and synergism of lopinavir, oseltamivir and ritonavir binding with SARS-CoV-2 Protease against COVID-19. Journal of Biomolecular Structure and Dynamics. 2020 Apr 14:1-6.

40. Alout H, Foy BD, Ivermectin: a complimentary weapon against the spread of malaria?. Expert review of anti-infective therapy, 2017;15(3):231-240.

41. Dixit A, Yadav R, Singh AV. Ivermectin: potential role as repurposed drug for COVID-19. Malays J Med Sci. 2020;27(4):154-8. https://doi.org/10.21315/mjms2020.27.4.15.

42. Caly L, Druce JD, Catton MG, Jans DA, Wagstaff KM. The FDA-approved drug ivermectin inhibits the replication of SARS-CoV-2 in vitro. Antiviral Res. 2020;178:104787. https://doi.org/10.1016/j.antiviral.2020.104787. 
43. Gupta D, Sahoo AK, Singh A. Ivermectin: potential candidate for the treatment of Covid 19. Braz J Infect Dis. 2020;24(4):369-71. https://doi.org/10.1016/j.bjid.2020.06.002.

44. Gendrot M, Andreani J, Jardot P, Hutter S, Delandre O, Boxberger M, et al. In vitro antiviral activity of doxycycline against SARS-CoV-2. Molecules. 2020;25(21):5064. https://doi.org/10.3390/molecules25215064.

45. Malek AE, Granwehr BP, Kontoyiannis DP. Doxycycline as a potential partner of COVID-19 therapies. IDCases. 2020;21:e00864. https://doi.org/10.1016/j.idcr.2020.e00864.

46. Bhowmick S, Dang A, Vallish BN, Dang S. Safety and Efficacy of Ivermectin and Doxycycline Monotherapy and in Combination in the Treatment of COVID-19: A Scoping Review. Drug safety. 2021 Apr 16:1-0.

47. Jin Z, Du X, Xu Y, Deng Y, Liu M, Zhao Y, Zhang B, Li X, Zhang L, Peng C, Duan Y. Structure of M pro from SARS-CoV-2 and discovery of its inhibitors. Nature. 2020:1-5.

48. Zhang L, Lin D, Sun X, Curth U, Drosten C, Sauerhering L, Becker S, Rox K, Hilgenfeld R. Crystal structure of SARS-CoV-2 main protease provides a basis for design of improved $\alpha$-ketoamide inhibitors. Science. 2020;368(6489):409-12.

49. Burley SK, Berman HM, Bhikadiya C, Bi C, Chen L, Di Costanzo L, Christie C, Dalenberg K, Duarte JM, Dutta S, Feng Z. RCSB Protein Data Bank: biological macromolecular structures enabling research and education in fundamental biology, biomedicine, biotechnology and energy. Nucleic acids research. 2019;47(D1):D464-74.

50. Trott O, Olson AJ, AutoDockVina: improving the speed and accuracy of docking with a new scoring function, efficient optimization, and multithreading J. Comput. Chem., 2010;31(2):455-61.

51. DassaultSystemes BIOVIA. (2017). Discovery studio modeling environment, Release. DassaultSystemes.

52. M.J. Frisch, et al., Gaussian 09, Revision B.01, Gaussian Inc., Wallingford CT, 2010.

53. R. Dennington, T. Keith, J. Millam, Gauss View, Version 4.1.2, Semichem, Inc., Shawnee Mission, KS, 2007.

54. Sanner MF. Python: a programming language for software integration and development. J Mol Graph Model. 1999;17(1):57-61.

55. Yuriev E, Agostino M, Ramsland PA. Challenges and advances in computational docking: 2009 in review. Journal of Molecular Recognition. 2011;24(2):149-64.

56. Berendsen HJ, van der Spoel D, van Drunen R. GROMACS: a message-passing parallel molecular dynamics implementation. Computer physics communications. 1995 ;91(1-3):43-56.

57. vanGunsteren WF, Billeter SR, Eising AA, Hünenberger PH, Krüger PK, Mark AE, Scott WR, Tironi IG. Biomolecular simulation: the GROMOS96 manual and user guide. VdfHochschulverlag AG an der ETH Zürich, Zürich. 1996;86.

58. Berendsen HJ, Postma JV, van Gunsteren WF, DiNola AR, Haak JR. Molecular dynamics with coupling to an external bath. The Journal of chemical physics. 1984;81(8):3684-90.

59. Kumari R, Kumar R, Open Source Drug Discovery Consortium, Lynn A. g_mmpbsa A GROMACS tool for high-throughput MM-PBSA calculations. Journal of chemical information and modeling. 2014;54(7):1951-62. 
60. Benson NC, Daggett V. A comparison of multiscale methods for the analysis of molecular dynamics simulations. The Journal of Physical Chemistry B. 2012;116(29):8722-31.

61. Kircik LH, Del Rosso JQ, Layton AM, Schauber J. Over 25 years of clinical experience with ivermectin: an overview of safety for an increasing number of indications. J Drugs Dermatol. 2016;15:325-32.

62. Khan SA, Zia K, Ashraf S, Uddin R, Ul-Haq Z. Identification of chymotrypsin-like protease inhibitors of SARS-CoV-2 via integrated computational approach. Journal of Biomolecular Structure and Dynamics. 2020:1-0.https://doi.org/10.1080/07391102.2020.1751298

63. Chowdhury P, Pathak P. Neuroprotective Immunity by Essential Nutrient "Choline" for the Prevention of SARS CoV2 Infections: An In Silico Study by Molecular Dynamics Approach. Chemical Physics Letters. 2020;761:138057.

64. Rana M, Chowdhury P. Perturbation of hydrogen bonding in hydrated pyrrole-2-carboxaldehyde complexes. Journal of molecular modeling. 2017;23(7):216.

65. Rana M, Chowdhury P. Studies on Size Dependent Structures and Optical Properties of CdSeS Clusters. Journal of Cluster Science. 2019;15:1-1.

66. Smitha M, Mary YS, Mary YS, Serdaroglu G, Chowdhury P, Rana M, Umamahesvari H, Sarojini BK, Mohan BJ, Pavithran R. Modeling the DFT structural and reactivity studies of a pyrimidine-6-carboxylate derivative with reference to its wavefunction-dependent, MD simulations and evaluation for potential antimicrobial activity. Journal of Molecular Structure. 2021;1237:130397. 


\section{Supplementary Files}

This is a list of supplementary files associated with this preprint. Click to download.

- Graphicalabstract.pdf

- SupplementaryMaterial.docx 